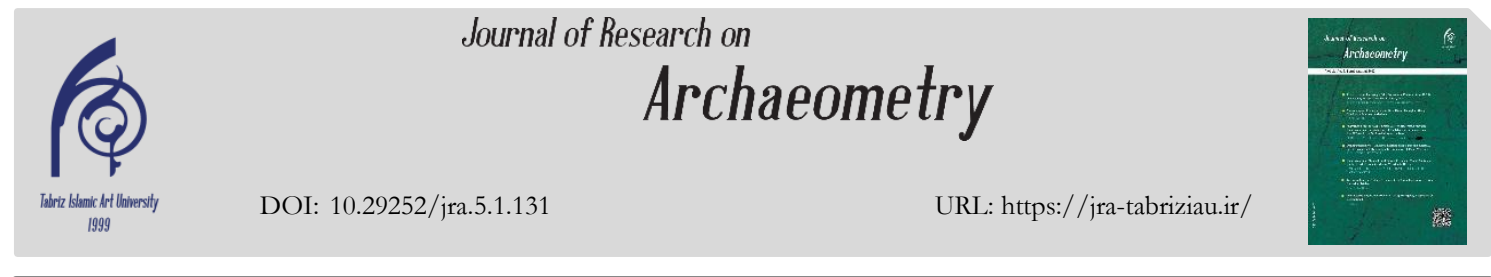

Original Paper

\title{
Validation of Infrared Scanner by the Assistance of Geomatic Documentation of the Historical Building of Etemad al-Saltanah
}

\author{
Mohammad Sadegh Taher Tolou Del ${ }^{1}$, Sina Kamali Tabrizi ${ }^{2 \star}$ \\ ${ }^{1}$ Associate Professor as a Member of Architecture Group, Shahid Rajaee Teacher Training University, \\ Tehran, IRAN \\ ${ }^{2}$ Ph.D Candidate of Architectural Engineering, Shahid Rajaee Teacher Training University, Tehran, IRAN
}

\begin{tabular}{ll}
\hline Received: 04/09/2019 & Accepted: 24/11/2019
\end{tabular}

\begin{abstract}
Since the historical buildings undergo a lot of changes and damages in the course of history, they are required to be documented. These changes might come about as a result of natural symptoms like rainfall, wind, earthquake, flood, explosion and/or by human beings (consciously or unconsciously). Therefore, efforts should be made in line with 3D documenting such buildings so that, besides precise identification of the buildings' current status and the damages imposed to them during the time, the future changes and damages' trends could be predicted, so enables us to prevent their continuation. The documentation system is selected according to the dimensions of the object, the density of the required point clouds and accuracy. Regarding that the current methods for laser-based or photography-based (photogrammetry) 3D reconstruction are expensive or complex, cost-effective infrared sensors, such as the structure sensor and the Kinect sensor, have been introduced as promising alternative tools. An infrared scanner, as a portable depthsensing scanner, consists of a color sensor and a depth sensor that are capable of capturing color images and depths of objects in the visible and accessible range. These sensors are commonly referred to as RGB-D cameras because they output standard RGB images from the camera that have an additional Depth channel per pixel (Fig. 2). The most recent development of the infrared documentation system is the portable Structural Sensor provided by Occipital in collaboration with Prime Sense. This small, lightweight, wireless sensor directly collects and records point clouds data and create three-dimensional modeling of interiors. Structure sensor is a new technology in metric documentation; therefore, the capabilities of this system have not been evaluated for documenting cultural heritage. According to the error introduced for the structure sensor, the scanner has a precision of more than $99 \%$ in objects between 0.4 and 3.5 meters; therefore, it is suitable for heritage documentation. The main purpose of this research is, therefore, to verify this claim based on projects captured through experimental tests, in order to confirm the suitability of this tool for cultural heritage documentation. The historical house of Etemad al-Saltanah was documented (Fig. 8 ) and processed to experimentally examine the structure sensor, the results of which were compared with the actual dimensions of the house (Table 4). Results of the research showed that this system of documentation is not suitable for $3 \mathrm{D}$ capturing and reconstructing historical buildings and does not have the required and claimed level of precision (Table 5). Also, the structure sensor precision was assessed for documenting museum objects through testing the scale model of Imam Mosque in Isfahan, Iran (Fig. 11). Results (Table 6) indicate that the structure
\end{abstract}

*Corresponding author: sina_kamali@yahoo.com 
sensor is only suitable for historical objects with dimensions between 0.3 and 2 meters, and has a precision of more than $95 \%$, which is acceptable according to the Cadastral spatial information regulation. The number of point clouds varies between $10^{3}$ and $10^{6}$ points in each capture (Fig. 12) and the capture dimensions are achievable considering a root-mean-square error up to $5 \mathrm{~m}^{3}$, beyond which is higher than the capability of the scanner. Pearson correlation test showed increasing errors of the scanner with enlarged sizes of objects (Table 3).

Keywords: Remote Sensing, Point Clouds, Historical Buildings, Restoration, Conservation 


\section{$\bigoplus_{\text {CrossMark }}$ تاريخى اعتمادالسلطنه \\ محمدصادق طاهر طلوع دل '، سينا كمالى تبريزى ז"}

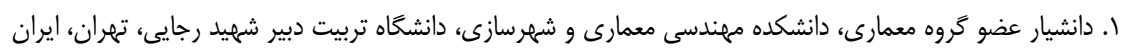

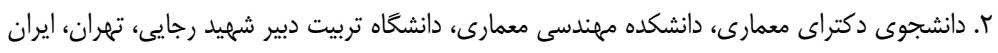

ازآنجايى كه روشهاى فعلى براى بازسازى سلبعدى مبتنى بر ليزر يا مبتنى بر عكس (فوتوگرامترى)، گرانقيمت يا يبيجيده هسـتند،

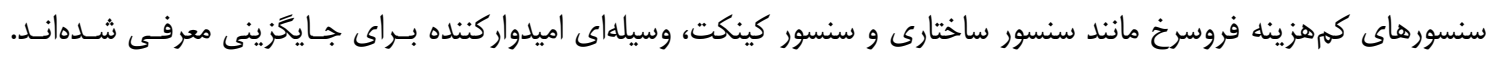

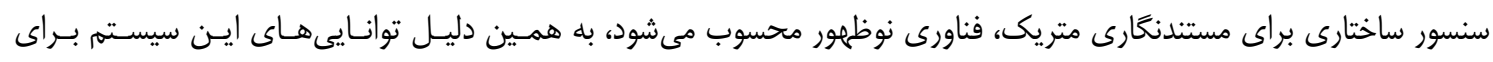
مستندنگارى ميراث فرهنگ

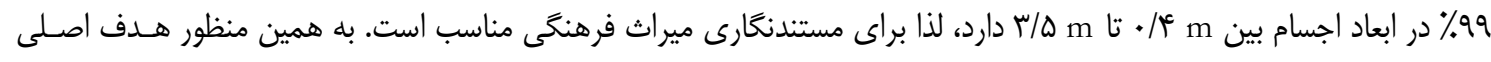

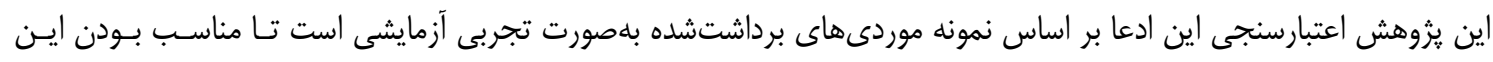

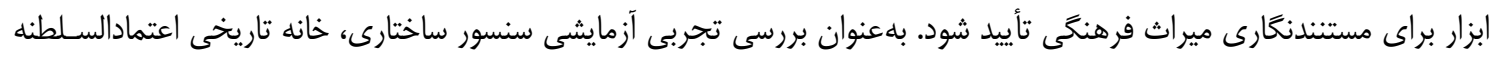

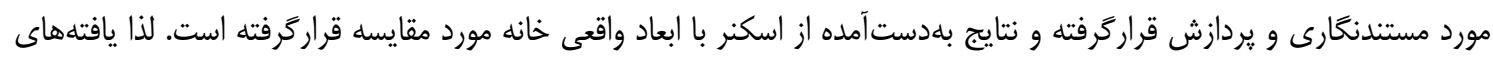

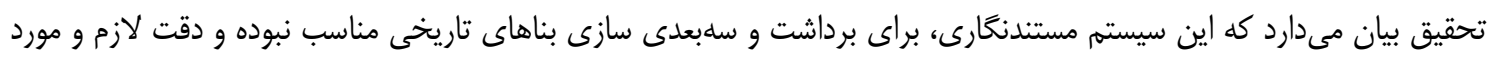

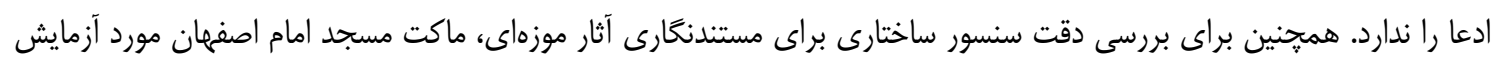

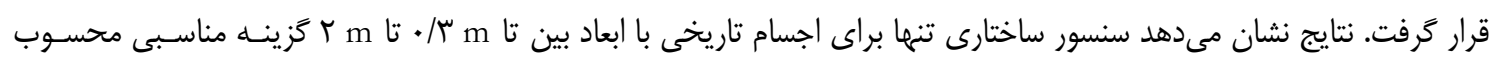

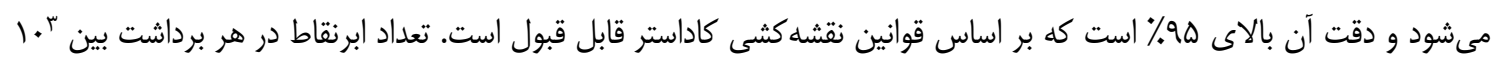

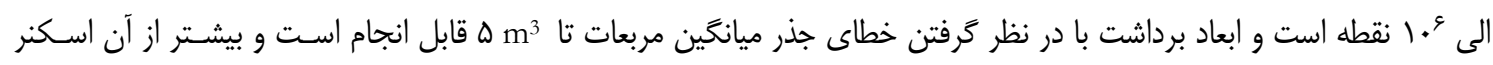

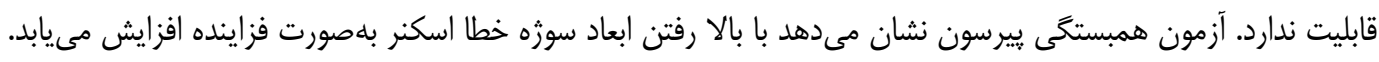

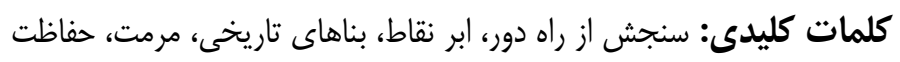

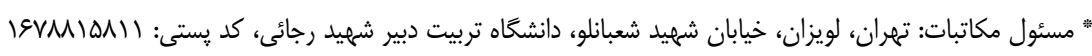
sina_kamali@yahoo.com : حست الكترونيكى C) حق نشر متعلق به نويسنده(كان) است و نويسنده تحت مجوز Creative Commons Attribution License به مجله اجازه مىدهد مقاله جاب شده را با ديخران به اشتراك بحذارد منوط بر اينكه حقوق مؤلف اثر حفظ و به به انتشار اوليه مقاله در اين مجله اشاره شود. 


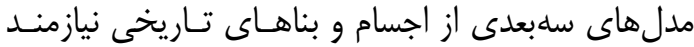
استفاده و بلهاركيرى ابزارهاى مستندنغارى هستيه. لـذا

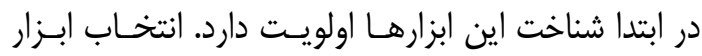

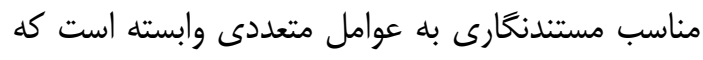
مهمترين آنها اشارهشده است (جدول ().

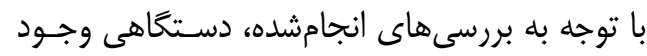

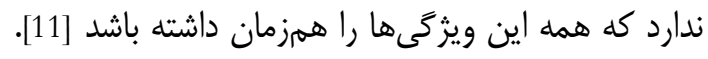
لذا ممكن است، براى بازسازى سلبعـدى مجسـمهـهـاى

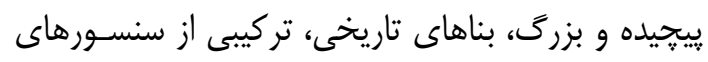

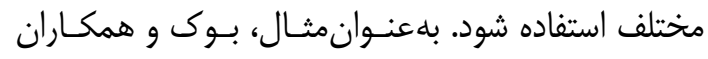

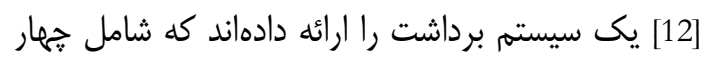
دوربين ديجيتال و دو اسكنر ليزرى است و اين سيسـتم توانايى بازسازى سلبعدى ميراث معمارى در يكى منطقـهـ

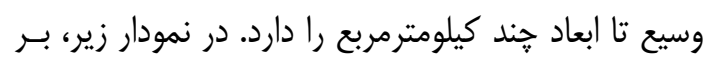
اساس يزوهش بليك، توانايى سيستمهاى مسـتندنغارى

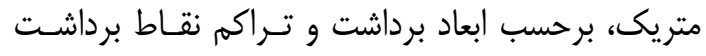

$$
\text { ارائهشده است (شكل () (). }
$$

همانطور كه ملاحظه مسىشـود در تحقيقـات جـامع

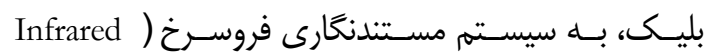
Scanner with Computational System Based on

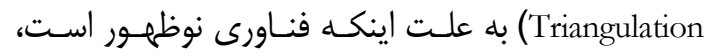

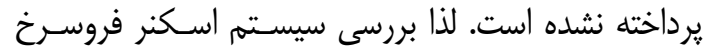

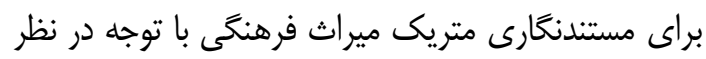
كرفتن تراكم ابر نقاط و توانايى ابعاد برداشت اهميت داردي

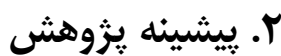

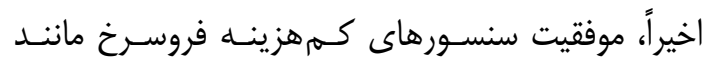

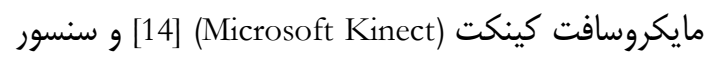

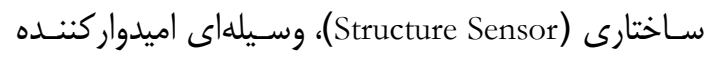

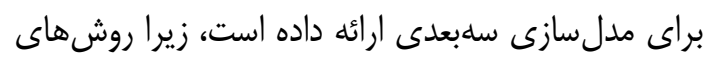

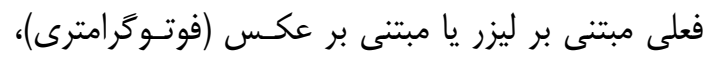

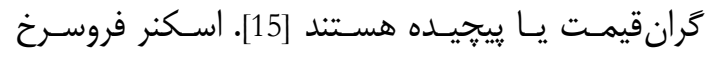

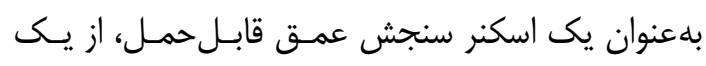
سنسور رنكى و يك سنسور عمق تشكيل شده است كه قادر به كرفتن تصاوير رنكى و عمق تصاوير اشياء موجود

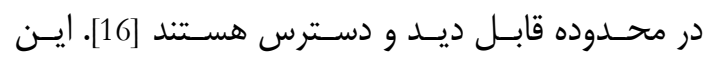

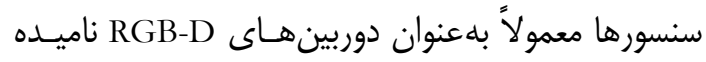

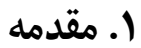

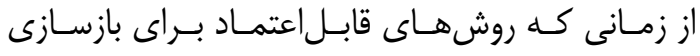

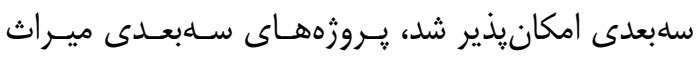

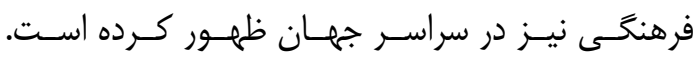

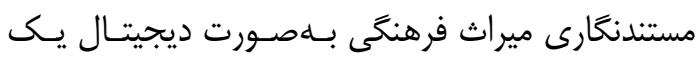

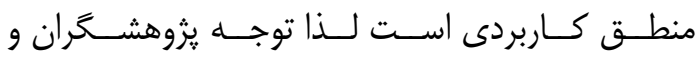
متخصصين حوزه حفاظت ميراث فرهنكى به اين فناورى در دو دهه كذشته، بلهصورت روزافزون بوده است. انكَيزه

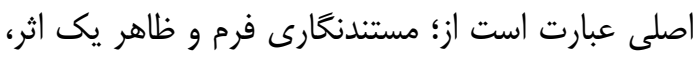

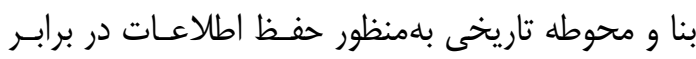
حوادث طبيعى مانند: سيل، زلزله، آتشسوزى و غيره [1]،

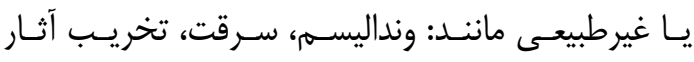

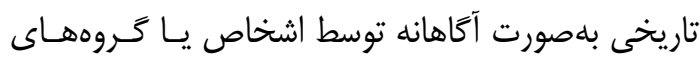
تروريستى و غيره [2]؛ فراهم كردن موزههاى مجـازى از

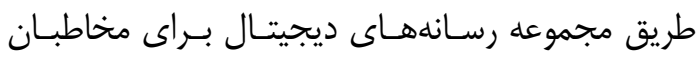

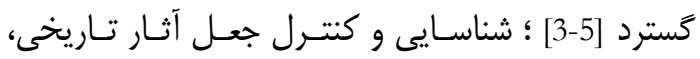

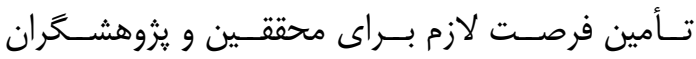

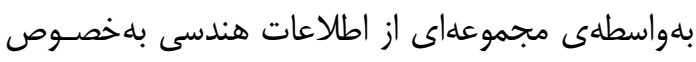

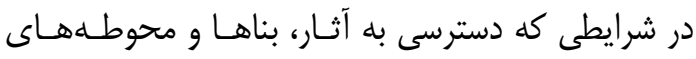

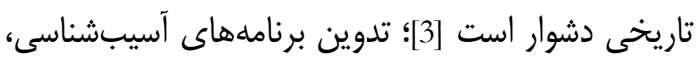

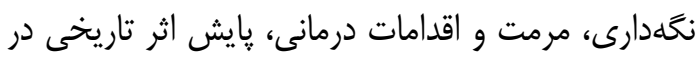

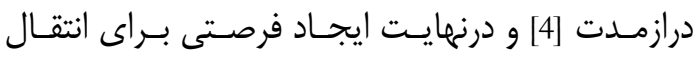

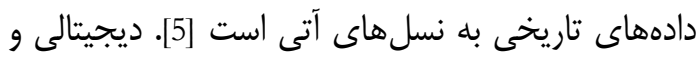

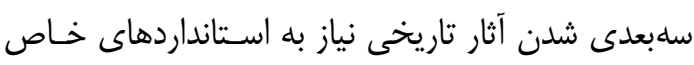

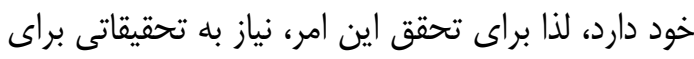

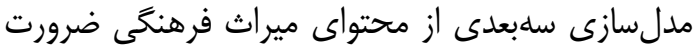

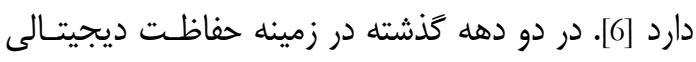

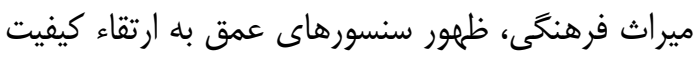

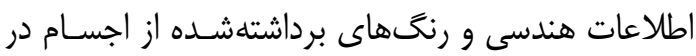

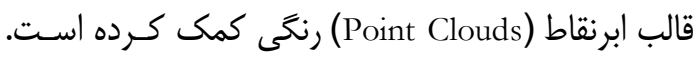

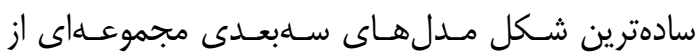

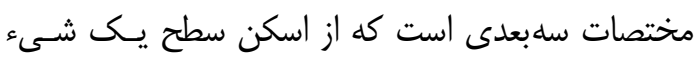

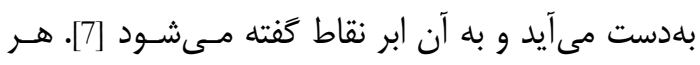

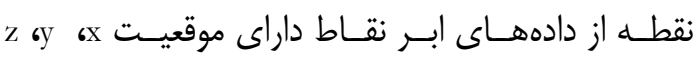

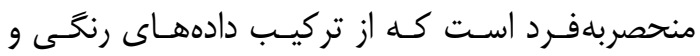
دادهاى عمق ايجادشده است [8]. براى توليد ابر نقاط و و 
جدول ا: عوامل و ويثَى هاى مهم براى انتخاب سيستم مستندنغارى مناسب

Table 1: Critical Factors and Properties for Choosing the Right Documentation System

\begin{tabular}{|c|}
\hline $\begin{array}{c}\text { توضيحات } \\
\text { Description }\end{array}$ \\
\hline 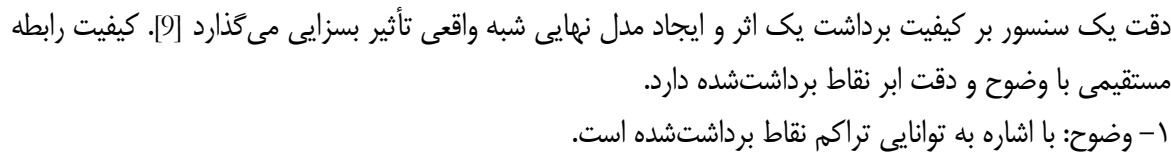 \\
\hline
\end{tabular}

The precision of a sensor affects the fidelity of the final model [9]. Quality has a direct relationship with the resolution and accuracy of the scanned point clouds.

Resolution. Referring to spacing of the samples.

Accuracy. Referring to the statistical variations among repeated measurements of a known value [10].

هزينه سنسورها مىتواند بلططور قابلتوجهى متفاوت باشد. بلعنوانمثال: سنسور كينكت مايكروسافت حدود يكصد

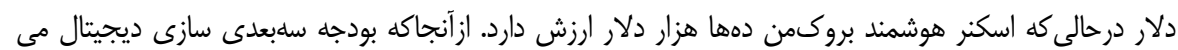

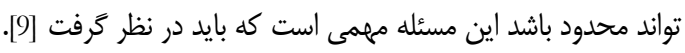

The cost of sensors can vary significantly. For instance: a Microsoft Kinect costs about one hundred dollars while a Breuckmann smart SCAN 3D-HE costs tens-of-thousands of Euro. Since the budget of digital preservation missions can be limited it is an important issue to consider [9].

محدوديتهايى مانند عدم وجود برق و دسترسى راحت به فضاى محوطه ميراث فرهنكى از مشكلات رايج است.

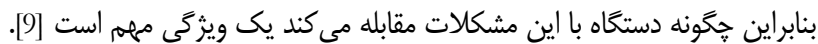

Constraints such as absence of electricity and location accessibility are common problems for some cultural heritage sites. Therefore how the device deals with these issues is also an important question [9].

سايتهاى ميراث فرهنكى زمان بازديد عمومى مشخصى دارند و مىتوانند تعداد زيادى بازديدكننده و كارمندان

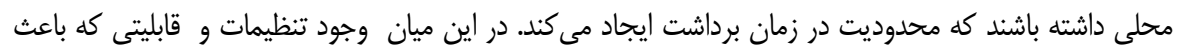

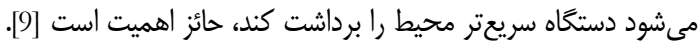
Cultural heritage sites can have a large number of visitors and local workers among other constraints that may limit the time to perform acquisition setting faster devices as more suitable [9].

آثار هنرى داراى مواد، ابعاد و برجستخى هاى متفاوتى هستند. سنسور دستخاه بايد بتواند جوابخوى جنين مسائلى

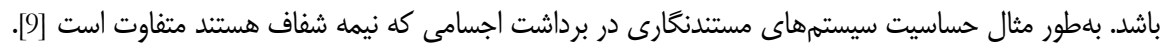
Artworks have arbitrary dimensions, materials and topologies. The sensor should be able to deal with such issues [9].

مربوط به تكراريذيرى يكسان مقدارهاى اندازهيرى شده است از يك سوزه در زمانهاى متفاوت است [10]. It is about the same reproducibility of the measured values of a subject at different times [10].

با توجه به نور موجود، باد، دما، تغييرات فشار و ديخر متغيرها در محيط، حذف عامل مخل دادهها در محاسبات

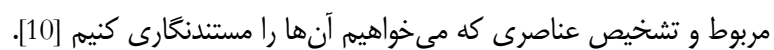

Relating to robustness under brightness, wind, temperature, and pressure changes, among other variables [10].

عوامل و ويزگى ها Factors and Properties

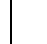

$-1$

Quality
Quيت




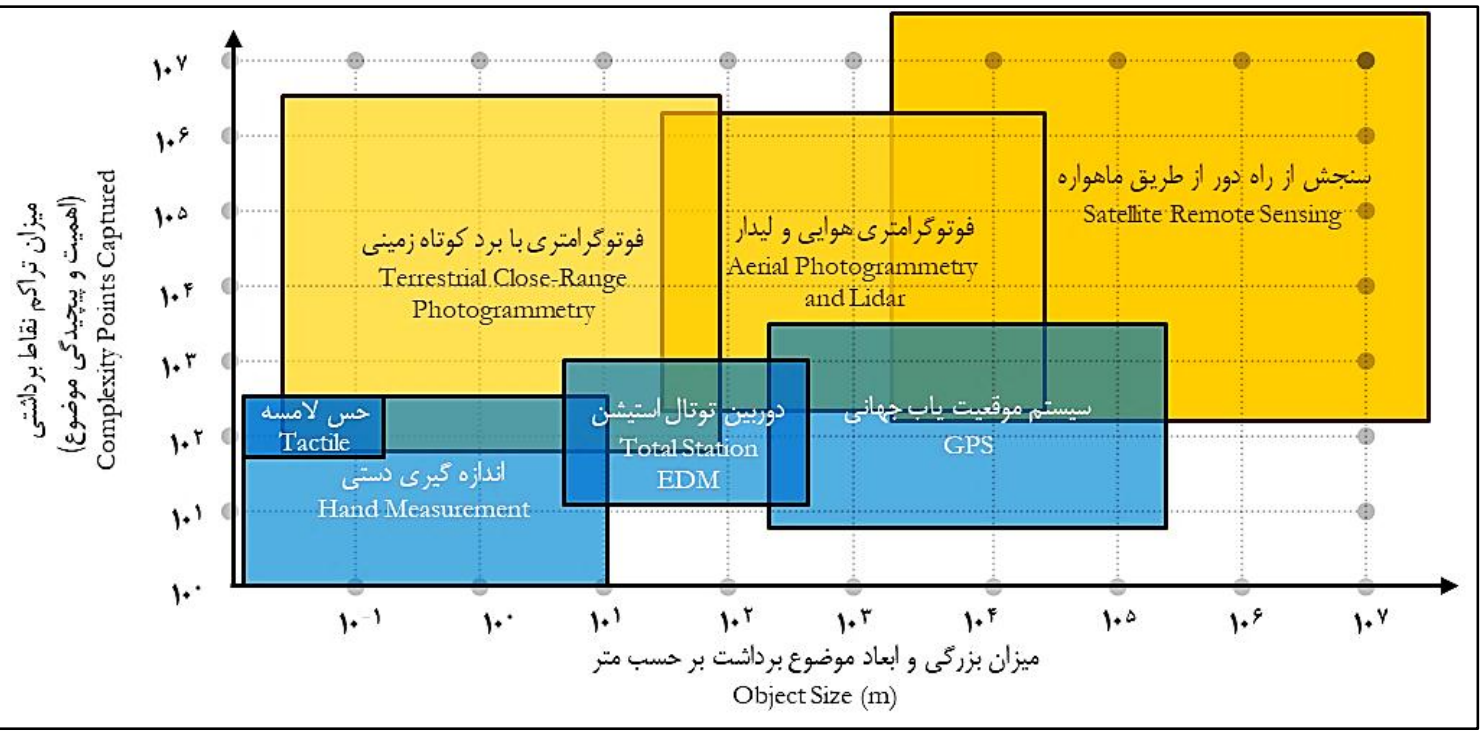

شكل (: سيستمهاى برداشت بر اساس ابر نقاط و ابعاد موضوع [13]

Fig. 1: Point Clouds Systems and Subject Dimensions [13]

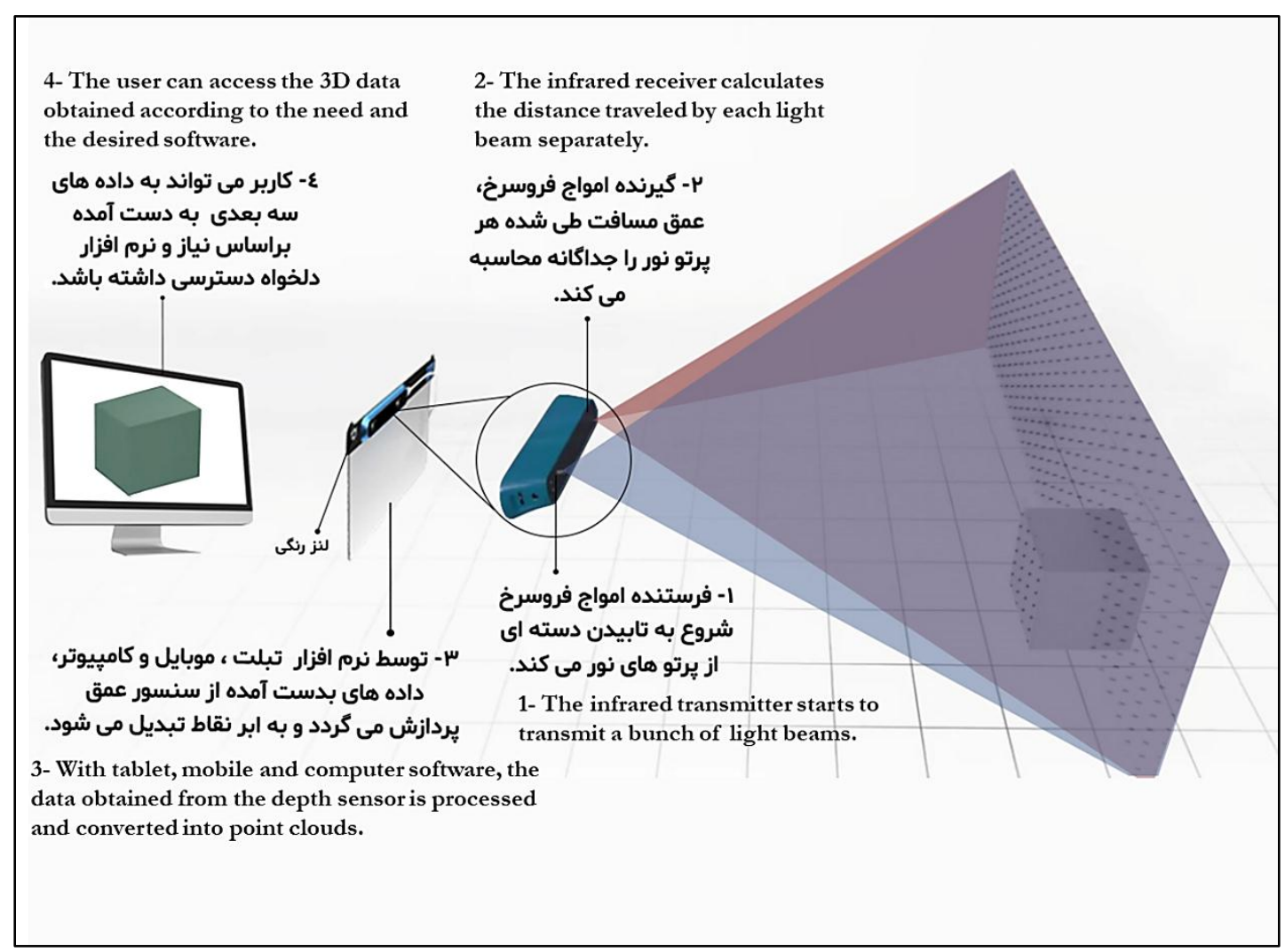

شكل r: سازوكار سنسور ساختارى

Fig. 2: Mechanism of Structural Sensor 
يكيارجهازسى فريمهاى سلبعدى متفـاوت از يــ فضـا

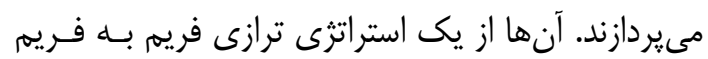

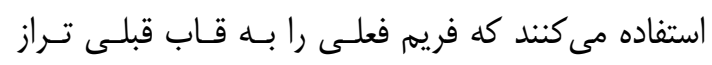

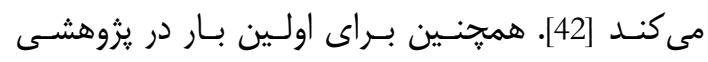

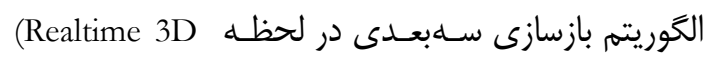
Reconstruction)

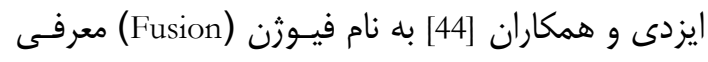

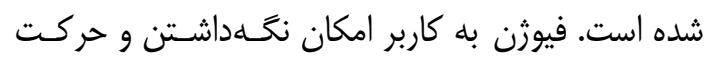

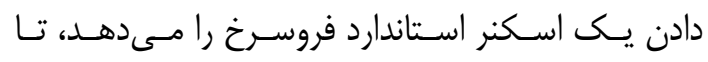
بلاسرعت بازسازىهاى سابعدى مفصلى از يـك صـحنه

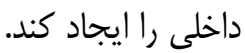

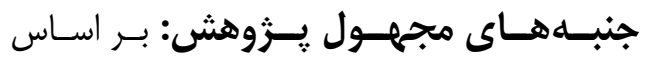

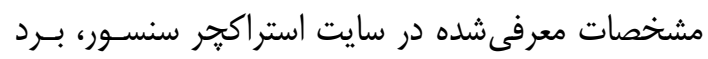

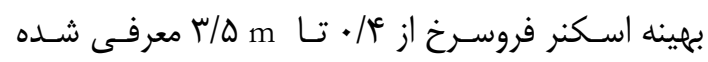

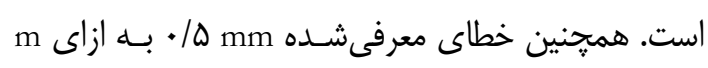

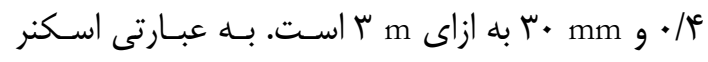

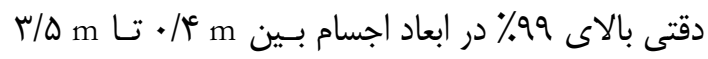

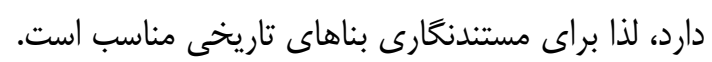

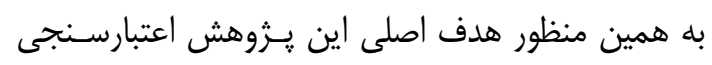

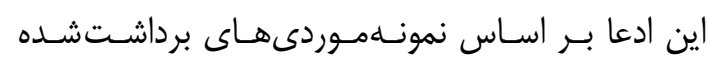

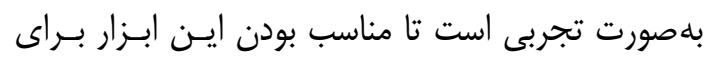

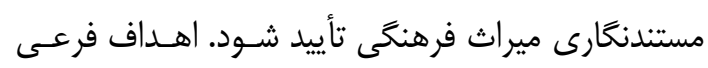

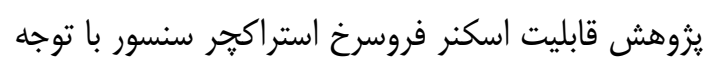

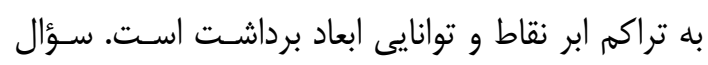

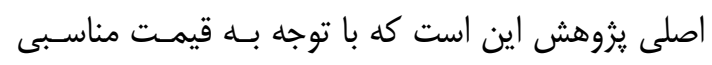

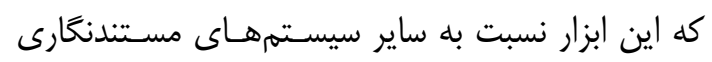

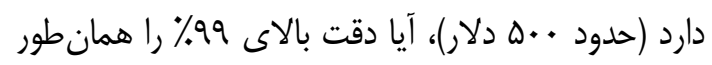

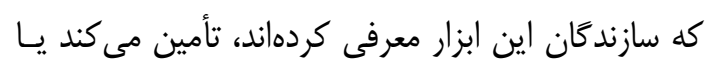

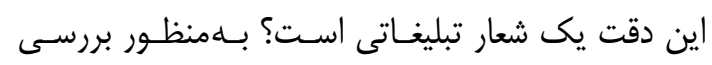

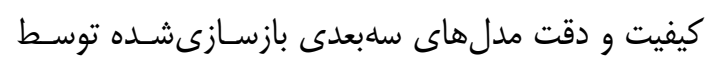

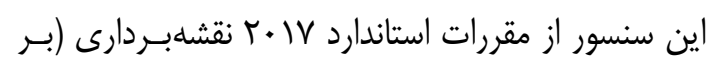
اساس مقررات كاداستر) 'يرداخته شده است.

\section{س. مواد و روشها}

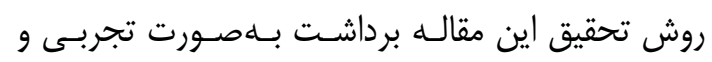

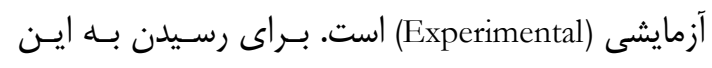

جريـان خروجـى از سنسـور سـاختارى داراى يــــ

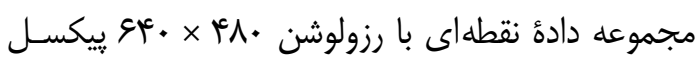

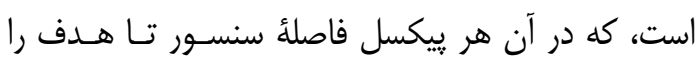

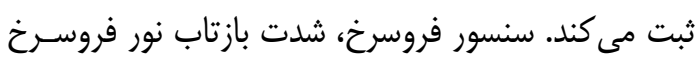
كه توسط يروز كتور IR: Infrared)

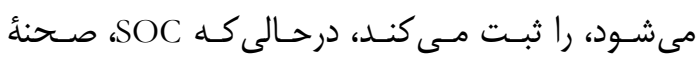

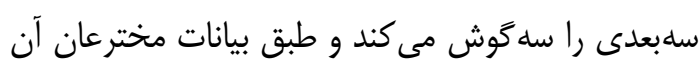

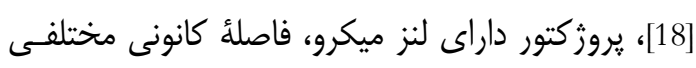

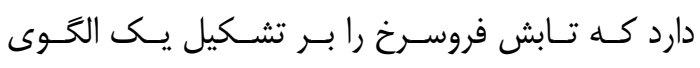

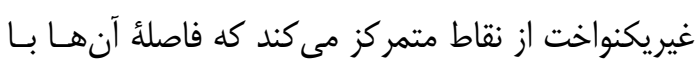

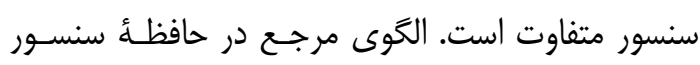

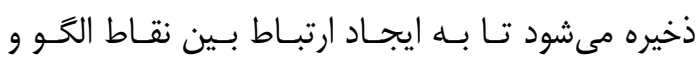

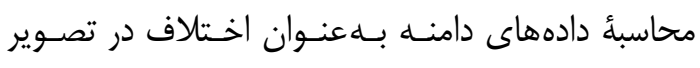

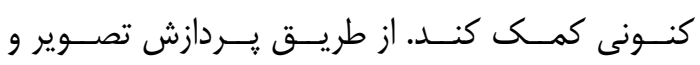

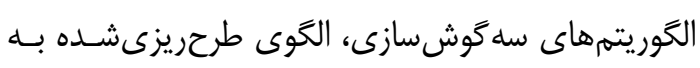
اطلاعات سلبعدى تبديل مىشود [19].

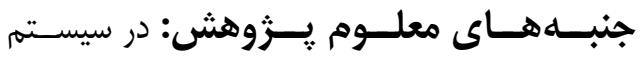

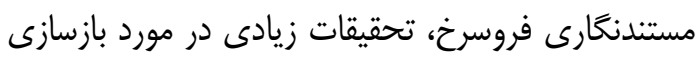

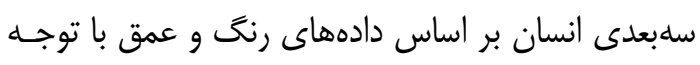

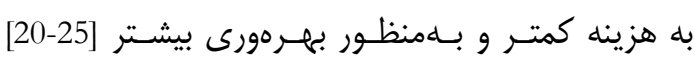

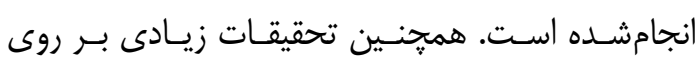

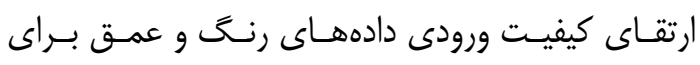

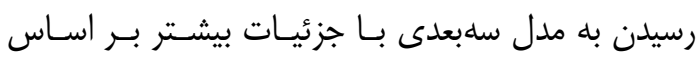

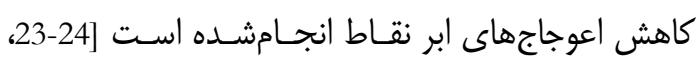

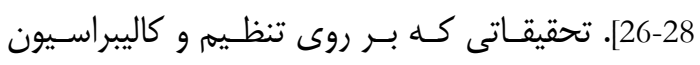

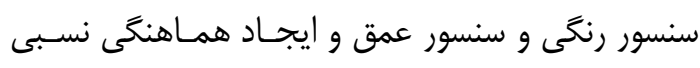

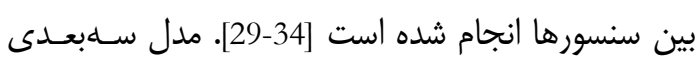
برداشتشده توسط اسكنر فروسرخ در اغلب موارد إد داراى

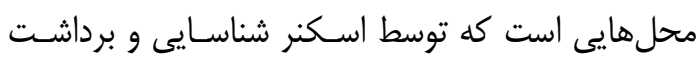

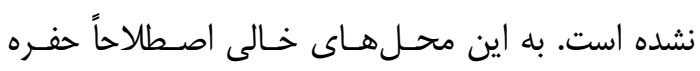

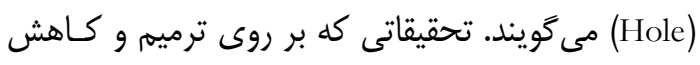

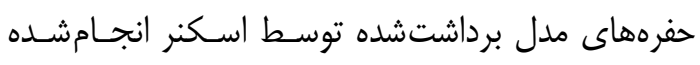

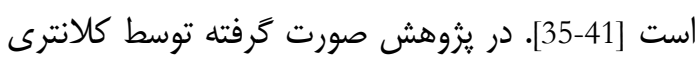
و همكاران ديوارهاى يك خانه كه ابعاد همكَى بيشـتر از

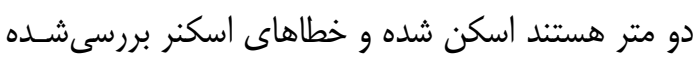

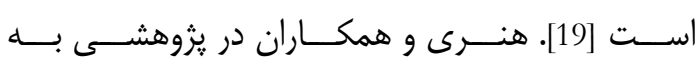




\section{ا ارزيابى دقت برداشت ها}
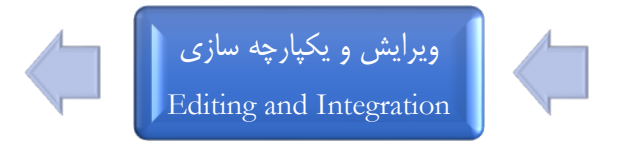

برداشت ميدانى

Field Scanning

شكل س: مراحل مستندنغارى با سنسور ساختارى

Fig. 3: Structural Sensor Documentation Steps

فرهنَّى شـده، تـاكنون اقـدامات مهمـى بـراى حفـظة

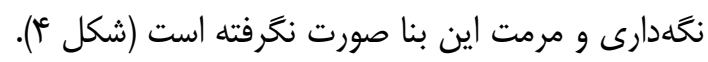

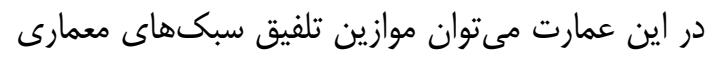

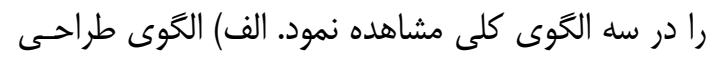

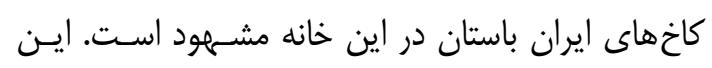

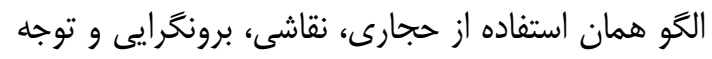

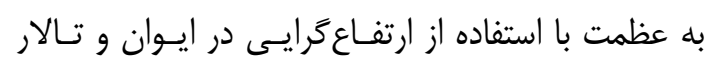

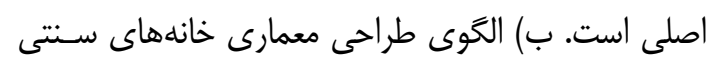

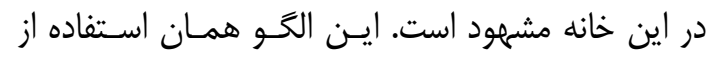

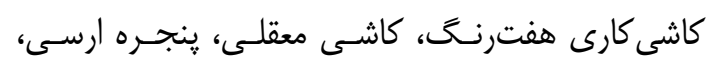

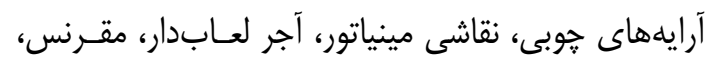

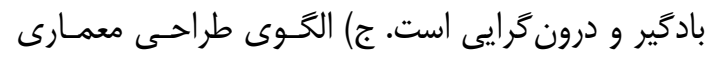

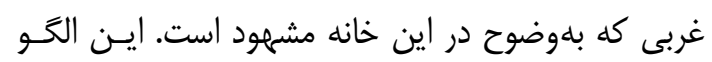
همان استفاده از سـتون كـرنتين، نقاشـ يرسـيكتيودار،
هدف، طى سه مرحله اقدام كَرديده است (شكل ऍّ). مرحله اول: برداشت ميدانى: در ايـن مرحلـه

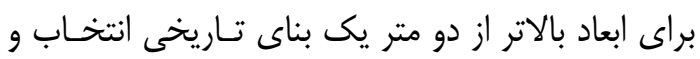
تمامى فضاهاى آن توسط اسكنر فروسرخ برداشت شــــ آنه

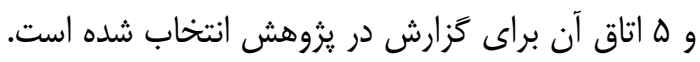

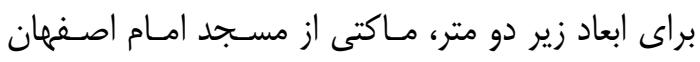

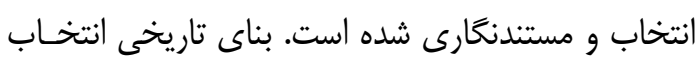
شده عمارت اعتمادالسلطنه واقع در خيابان يانزده خرداد،

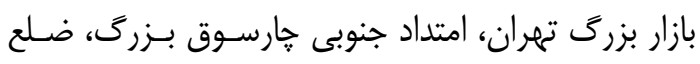

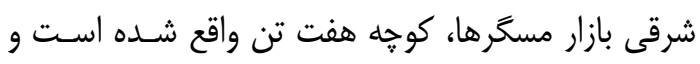

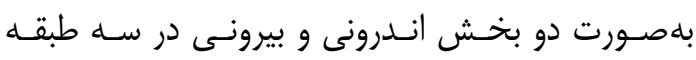

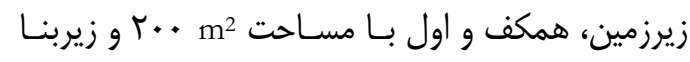

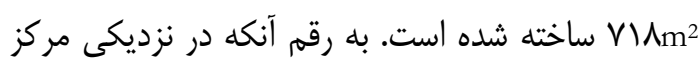

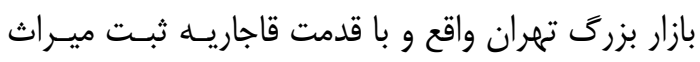
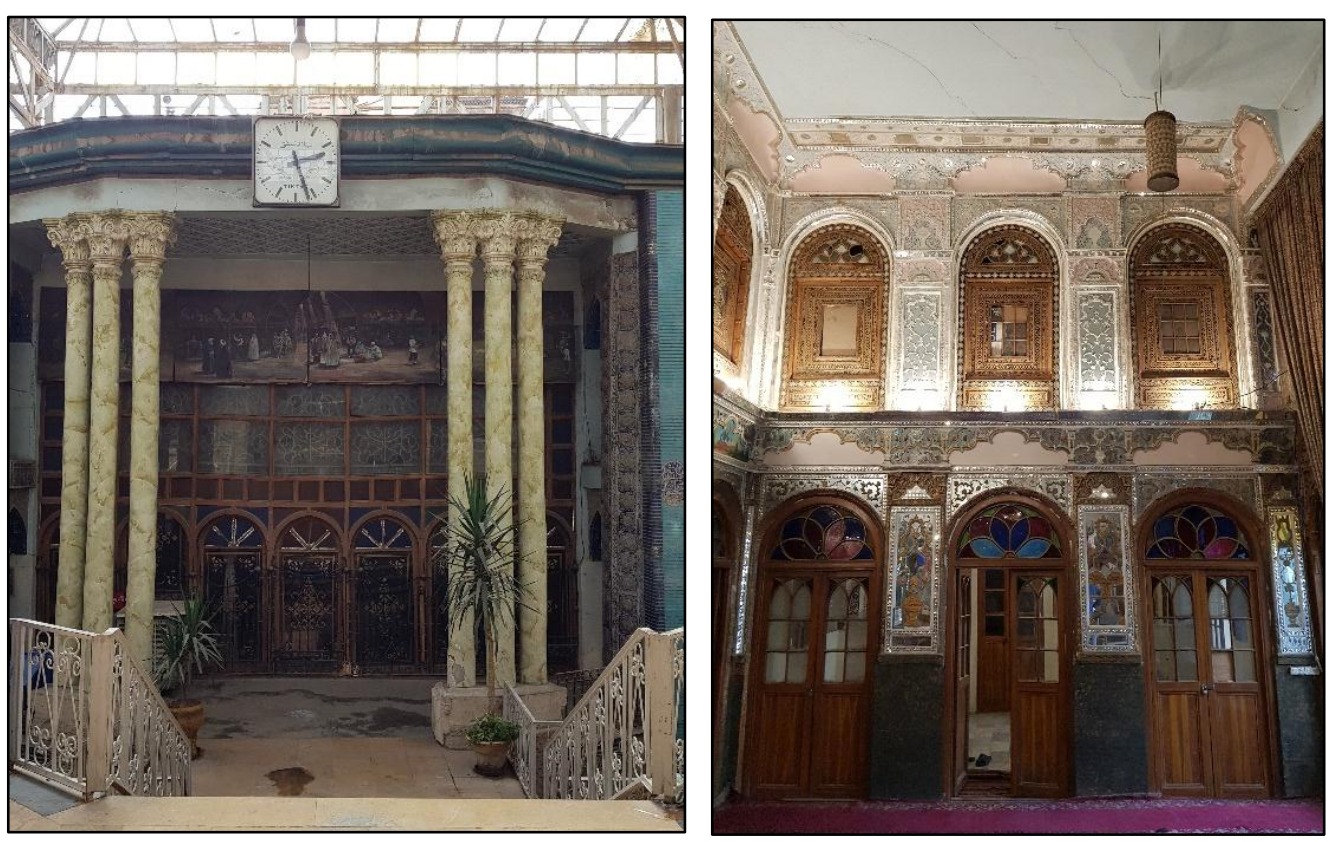

شكل عا: عمارت اعتمادالسلطنه

Fig. 4: The E'etemad Al-Saltaneh 
جدول r: ابعاد بلدست آمده واقعى و ابعاد بهدستآمده از اسكنر

Table 2: Actual Dimensions and Scanner Dimensions

\begin{tabular}{|c|c|c|c|}
\hline $\begin{array}{l}\text { ابعاد بهدستآمده از اسكنر (متر) } \\
\text { Scanner Dimensions (m) }\end{array}$ & $\begin{array}{l}\qquad \text { ابعاد واقعى (متر) } \\
\text { Actual Dimensions (m) }\end{array}$ & $\begin{array}{c}\text { ابعاد } \\
\text { Dimensions }\end{array}$ & $\begin{array}{c}\text { اتاق } \\
\text { Room }\end{array}$ \\
\hline 3.332 & 4.381 & $\begin{array}{l}\text { ديوار } 1 \\
\text { Wall } 1\end{array}$ & \multirow{4}{*}{$\begin{array}{c}\text { اتاق } 1 \\
\text { Room } 1\end{array}$} \\
\hline 1.827 & 2.253 & ديوار r 2 & \\
\hline 1.762 & 2.935 & $\begin{array}{l}\text { ديوار } 3 \\
\text { Wall } 3 \\
\end{array}$ & \\
\hline 3.505 & 4.387 & - & \\
\hline 2.341 & 2.549 & $\begin{array}{l}\text { ديوار I } 1 \\
\text { Wall } 1\end{array}$ & \multirow{4}{*}{$\begin{array}{c}\text { r اتاق } 2 \\
\text { Room } 2\end{array}$} \\
\hline 4.105 & 4.403 & $\begin{array}{l}\text { ديوار r } 2 \\
\text { Wall } 2\end{array}$ & \\
\hline 2.304 & 2.548 & $\begin{array}{l}\text { ديوار } 3 \\
\text { Wall } 3\end{array}$ & \\
\hline 4.006 & 4.352 & $\begin{array}{l}\text { ديوار } 4 \\
\text { Wall } 4\end{array}$ & \\
\hline 4.207 & 4.803 & - ديوار I 1 & \multirow{4}{*}{$\begin{array}{c}\text { اتاق } 2 \\
\text { Room } 3\end{array}$} \\
\hline 4.503 & 4.754 & $\begin{array}{l}\text { ديوار } \\
\text { Wall } 2 \\
\end{array}$ & \\
\hline 7.109 & 8.405 & ديوار ب & \\
\hline 7.006 & 8.156 & $\begin{array}{l}\text { ديوار } 4 \\
\text { Wall } 4\end{array}$ & \\
\hline 4.102 & 4.407 & - ديوار I 1 & \multirow{4}{*}{$\begin{array}{c}\text { اتاق } 1 \\
\text { Room } 3\end{array}$} \\
\hline 4.206 & 4.504 & $\begin{array}{l}\text { ديوار } 2 \\
\text { Wall } 2\end{array}$ & \\
\hline 1.906 & 1.902 & 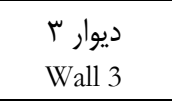 & \\
\hline 1.508 & 1.875 & $\begin{array}{l}\text { ديوار } 4 \\
\text { Wall } 4\end{array}$ & \\
\hline 5.305 & 4.632 & $\begin{array}{l}\text { ديوار } 1 \\
\text { Wall } 1\end{array}$ & \multirow{4}{*}{$\begin{array}{c}\text { اتاق } 1 \\
\text { Room } 5\end{array}$} \\
\hline 5.258 & 4.529 & $\begin{array}{l}\text { ديوار } 2 \\
\text { Wall } 2\end{array}$ & \\
\hline 2.994 & 3.326 & $\begin{array}{l}\text { ديوار } 3 \\
\text { Wall } 3\end{array}$ & \\
\hline 2.894 & 3.253 & $\begin{array}{l}\text { ديوار } 4 \\
\text { Wall } 4\end{array}$ & \\
\hline
\end{tabular}




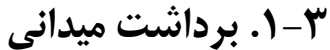

در ايـن مرحلـه بــا اسـتقرار سنسـور سـاختارى (اسـكنر

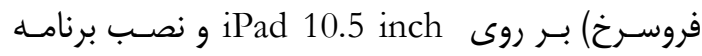

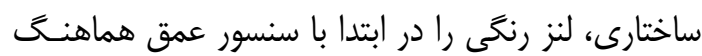

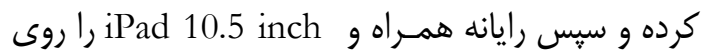
يك شبكه واى فاى داخلى متصـل مسى كنـيه. برنامـهـ را روى رايانسه Skanect 3D Scanning Software همراه نصب كرده و در اين حالت سه دستخاه 10.5

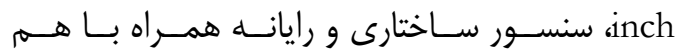

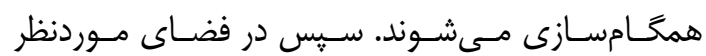

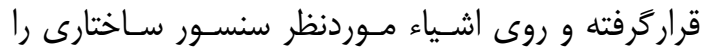

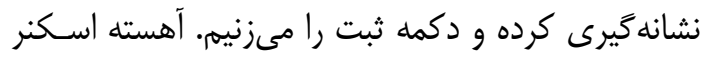
را در يكى نقطه ثابت به سمت تمـامى اشـياء موجـود در

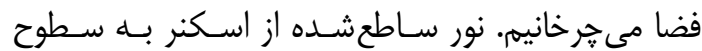

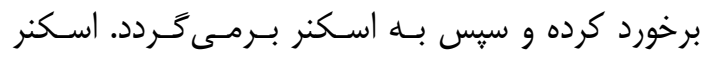

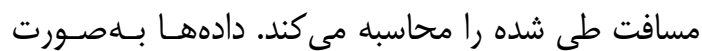

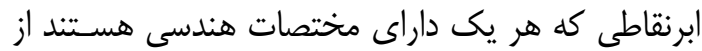

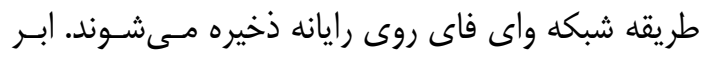
نقاط ثبتشده (شكل ه)، تنهـا نشـان دهنــده مختصـات

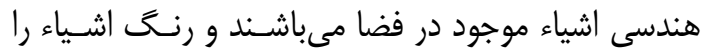

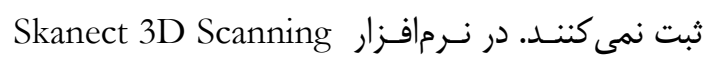

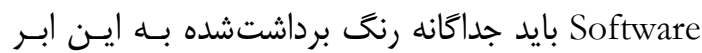

كجبرى كلوخى، نقاشى رئال، نقاشى ويتراى است [45].

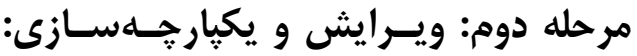

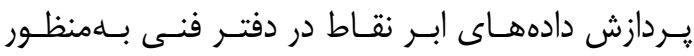

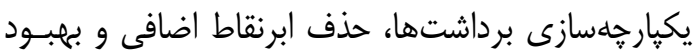
كيفيت ابرنقاط برداشت شده است؛

\section{مرحله سوم: ارزيــابى دقـت برداشـتهـــا:}

ارزيابى دقت برداشتها از طريق مقايسه ابعاد واقعى بنـا

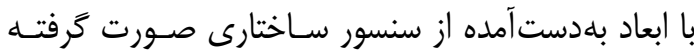

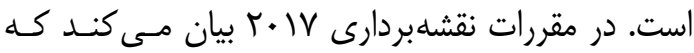
نقشهبرداران داراى مجوز بايد اطمينان حاصل كنتـد كـهـ

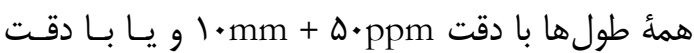

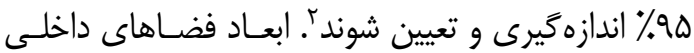

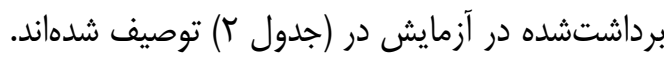

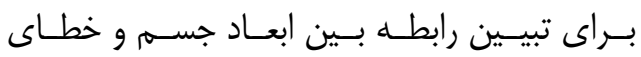

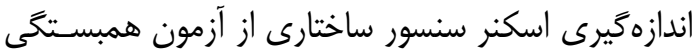

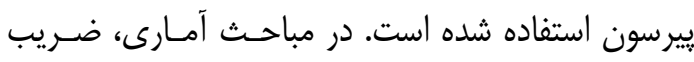
همبستكى ييرسون ميزان همبستخى خطى بين دو متغير

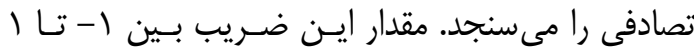
تغيير مى كند كه "(|) به معناى همبستخى مثبت كامـل،

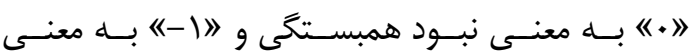

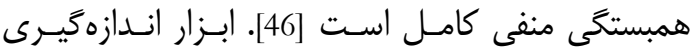
يزوهش، نرمافزار SPSS نسخه +r است.
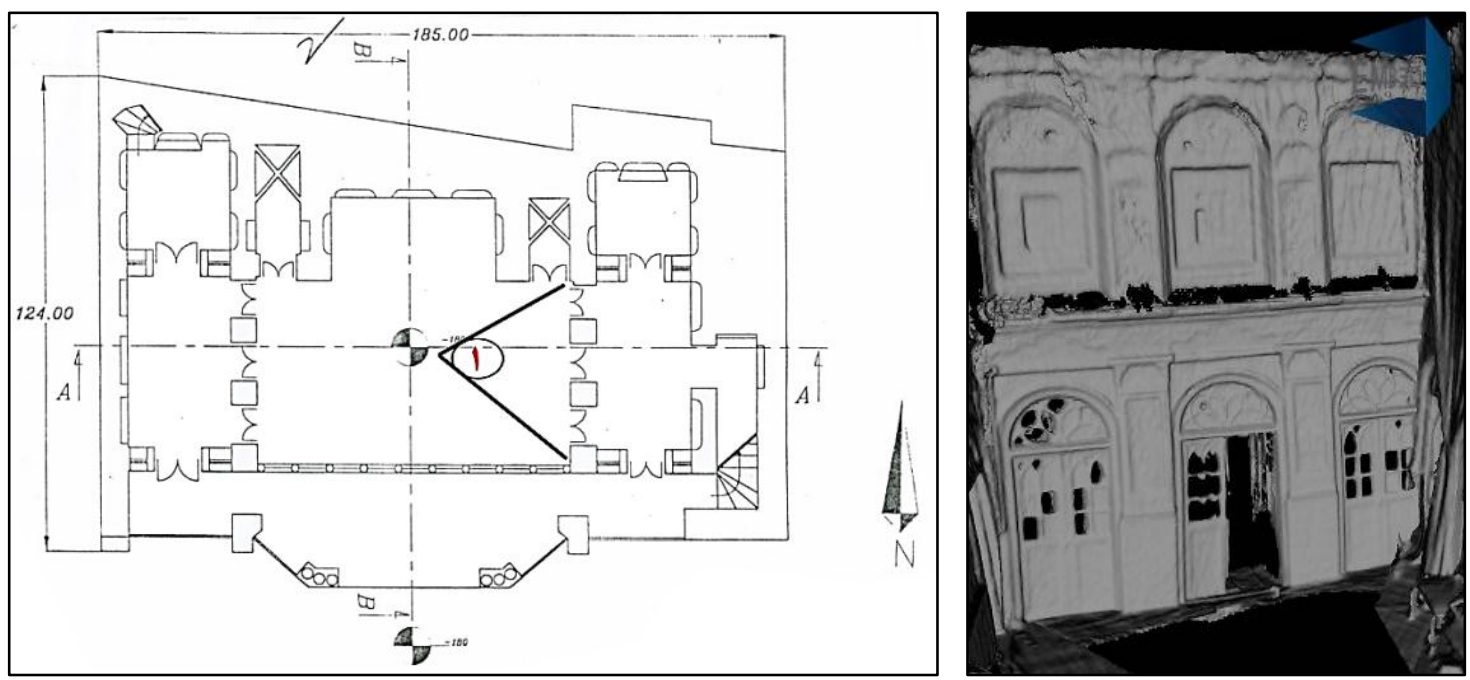

شكل ه: برداشت ا كه بر روى يلان همكف، محل استقرار اسكنر مشخصشده است.

Fig. 5: Scanning 1, indicated on the ground plan, where the scanner is located. 
روى عوارض برداشتشده مانند سطوح و اجسـام) قابـل

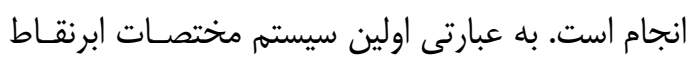

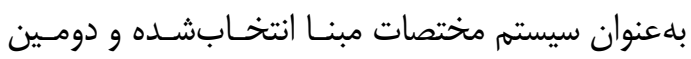
ابرنقاط بر اساس نقاط مشـترك بــه سيسـتهم مختصـات

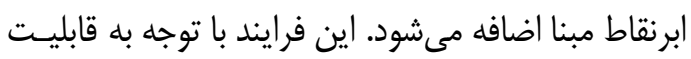

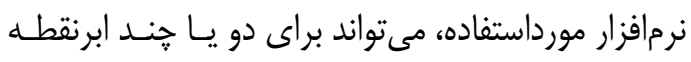
مختلف بلهور همزمان انجام شود (شـكل V). همجنـين درصورتى كه موقعيت استقر ارها در يك سيستم مختصات

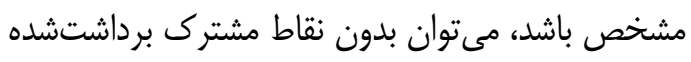

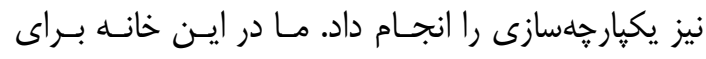

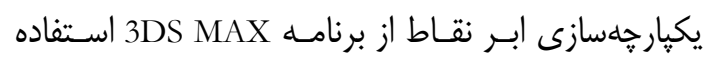

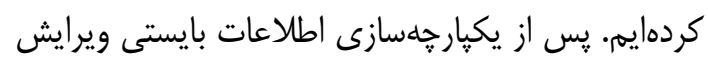

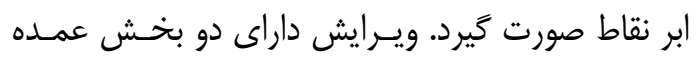

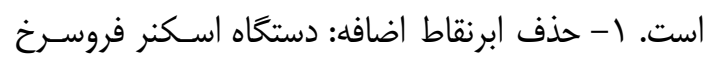

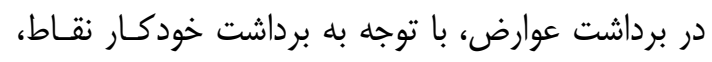

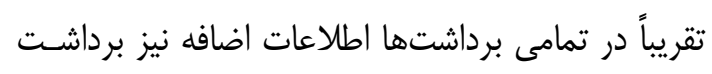

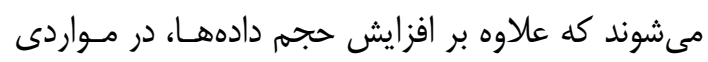

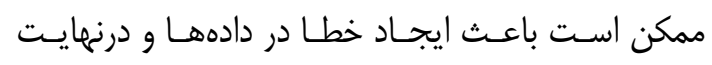

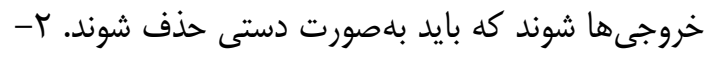

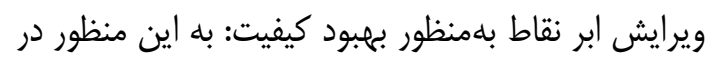

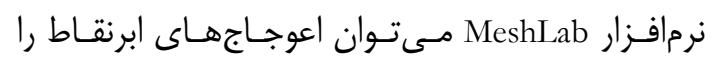

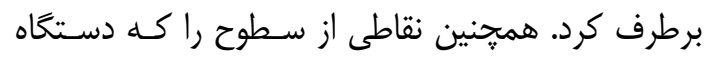

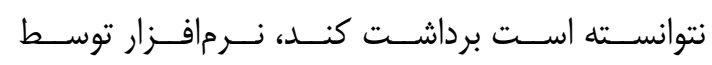

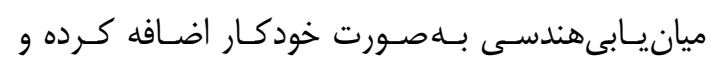

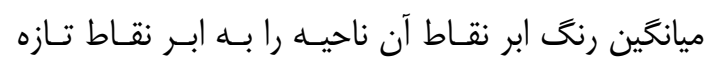
ايجادشده نسبت مى دهد.

\section{س-ب. ارزيابى دقت برداشتها}

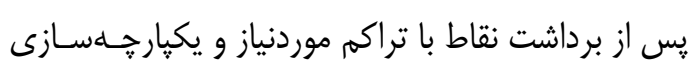

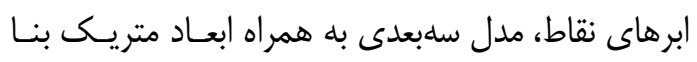

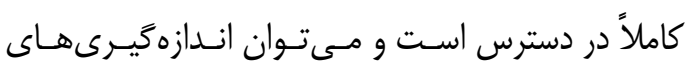

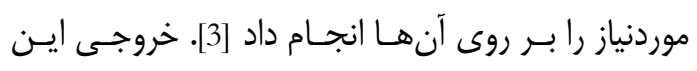

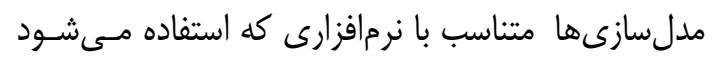

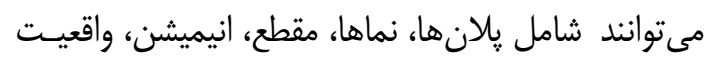

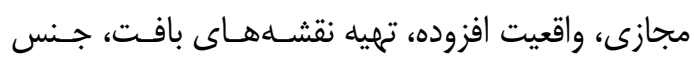

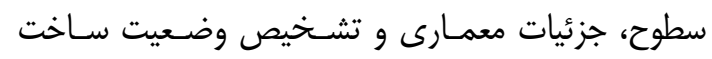
بناى تاريخى مزبور باشند (شكل ^).

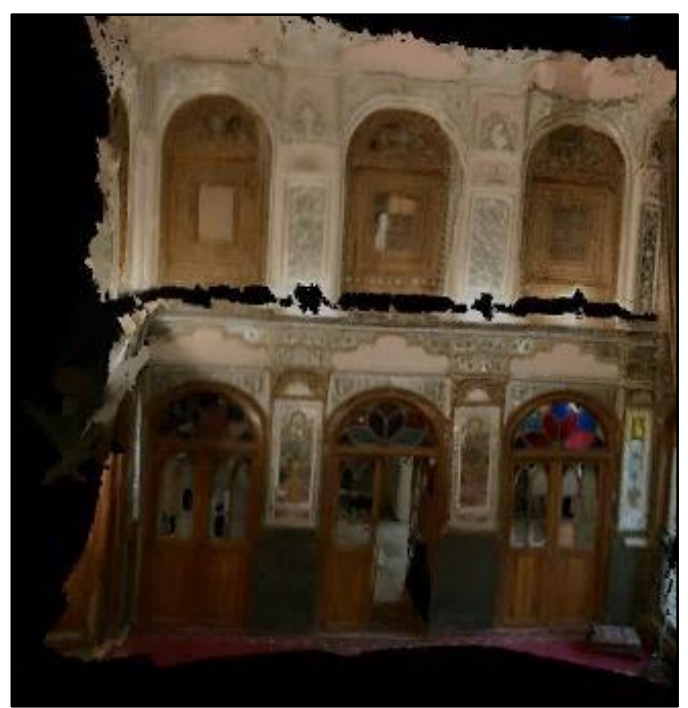

شكل و: رنح ابر نقاط توسط لنز رنكى RGB و توسط نرمافزار به نقاط مربوطه به برداشت ا نسبت داد شده است.

Fig. 6: Point Clouds color has been attached to the Scanning 1 by RGB lens and software.

نقاط اختصاص يابد (شكل 9). شبكه برداشت ابر نقـاط،

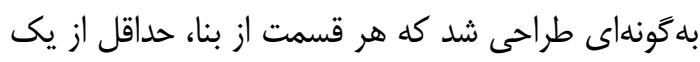

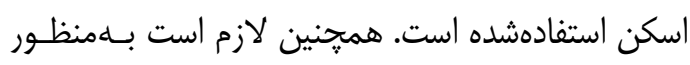

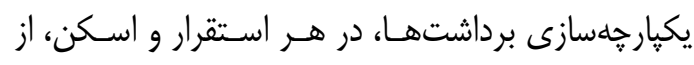

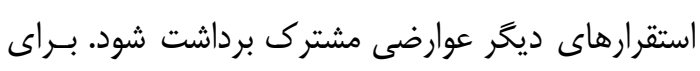

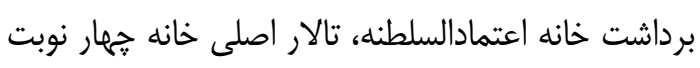

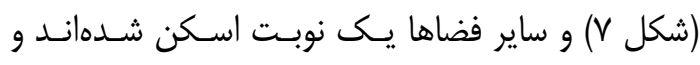

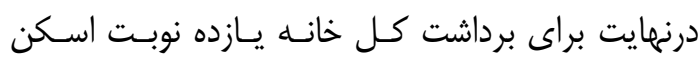

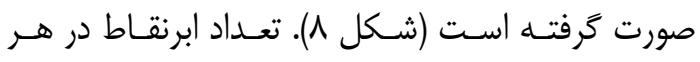

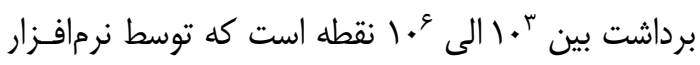
3DS MAX محاسبهشده استّ.

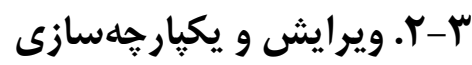

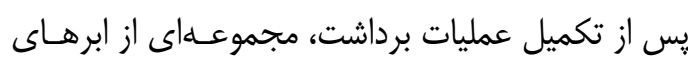

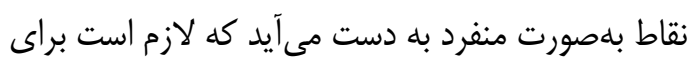

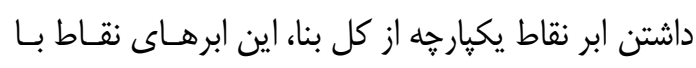

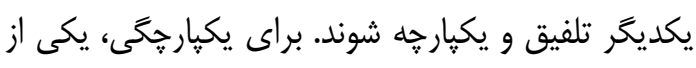

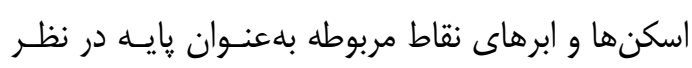

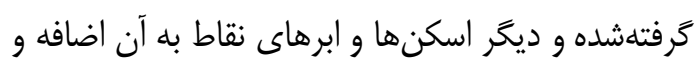

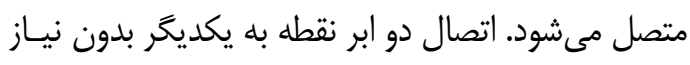

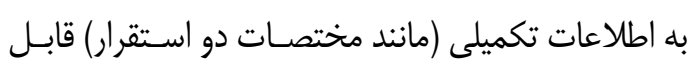
انجام است و صرفاً با داشتن حداقل سه نقطه مشترى (بر 

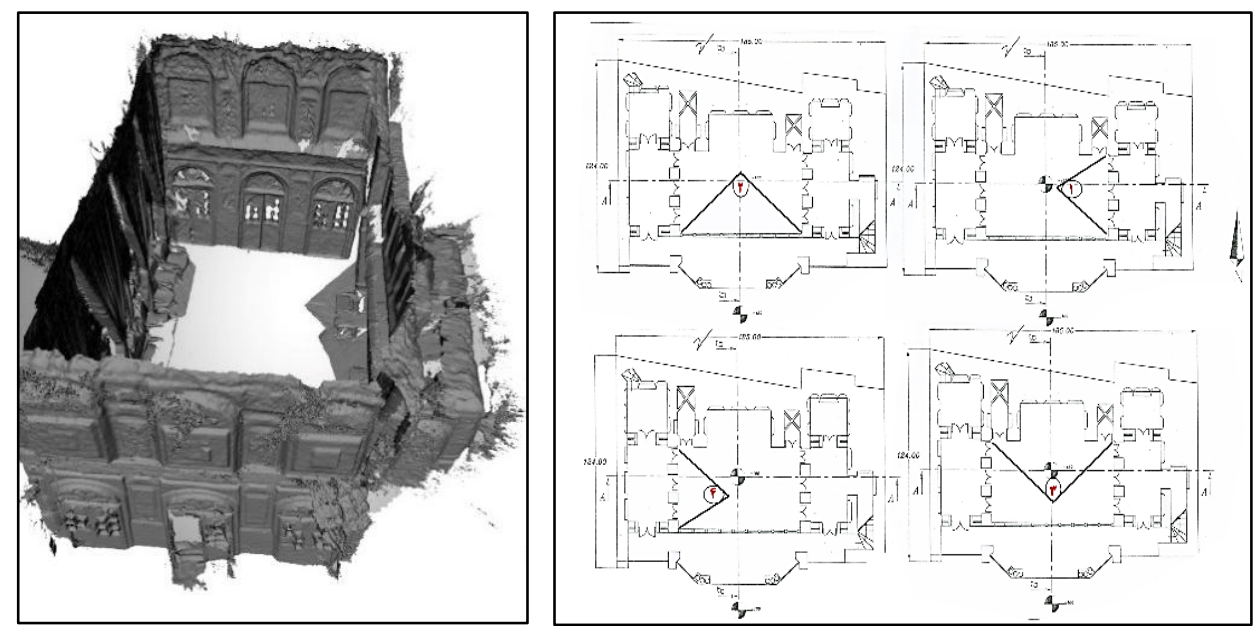

شكل У: يك ديوار بلعنوان مبنا انتخابشده و ساير ديوارها به ديوار مبنا اضافهشه، تالار اصلى أ نوبت اسكن شده است.

Fig. 7: One wall selected as the base and the other walls added to the base wall, the main hall being scanned 4 times.

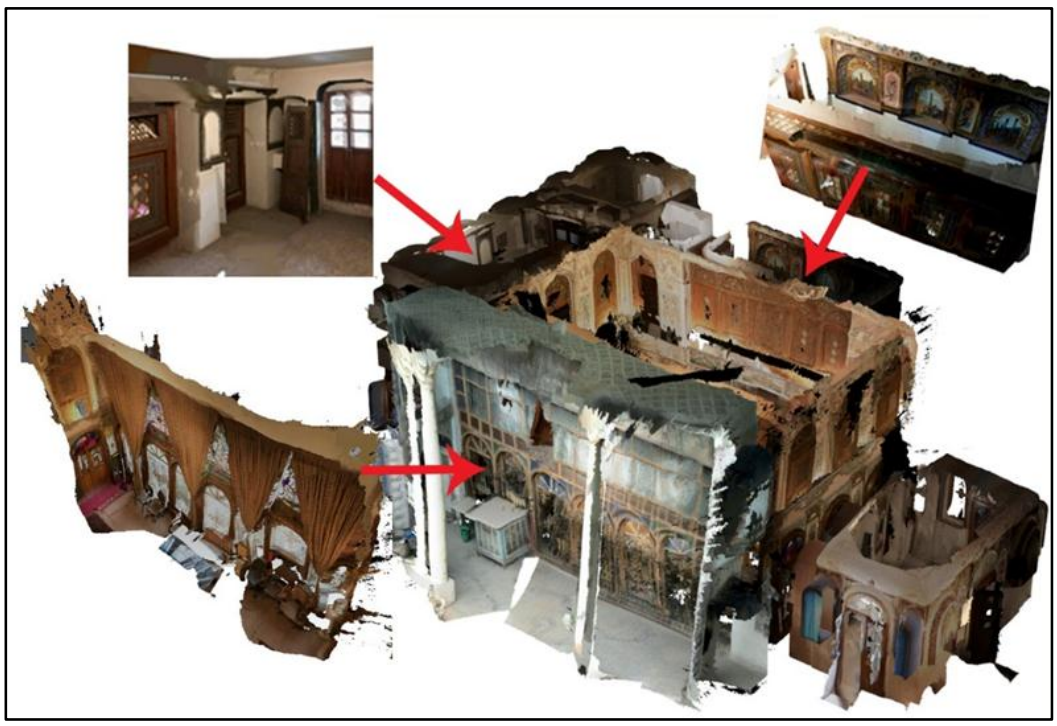

شكل ^: براى رسيدن به مدل سهبعدى كل خانه، Iا نوبت اسكن انجامشده است.

Fig. 8: 11 scans were performed to achieve the 3D model of the entire house.

$$
\begin{array}{r}
A_{e}=\text { true }_{d}-\text { model }_{d} \\
R_{e}=\frac{A_{e}}{\text { true }_{d}} \\
M R E=\frac{\sum_{i=1}^{n}\left(R_{e} i\right)}{n} \\
R M S E=\sqrt{\frac{\sum_{i=1}^{n}\left(A_{e} i\right)^{2}}{n}}
\end{array}
$$

در شكل 9، محور افقى، ديوارهاى اتاقهـا را نشـان

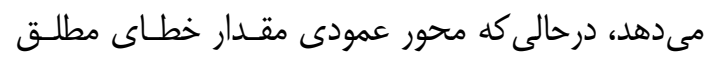

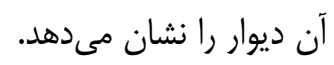

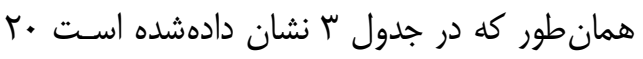

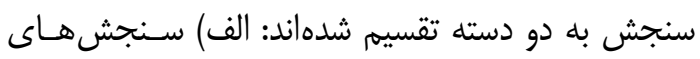
بـهـدســآمــده از ابعـاد واقعى ســاختمان و ب) ابعـاد

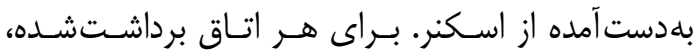
خطاهـاى مطلـق: (Absolute error) و نسـبى ( Relative error

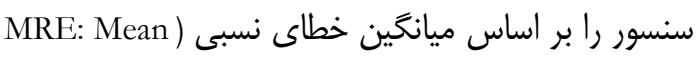
Relative Error ارزيابى شود. (RMSE: Root-Mean-Square Error)

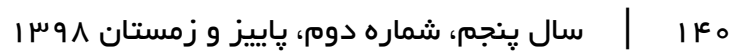




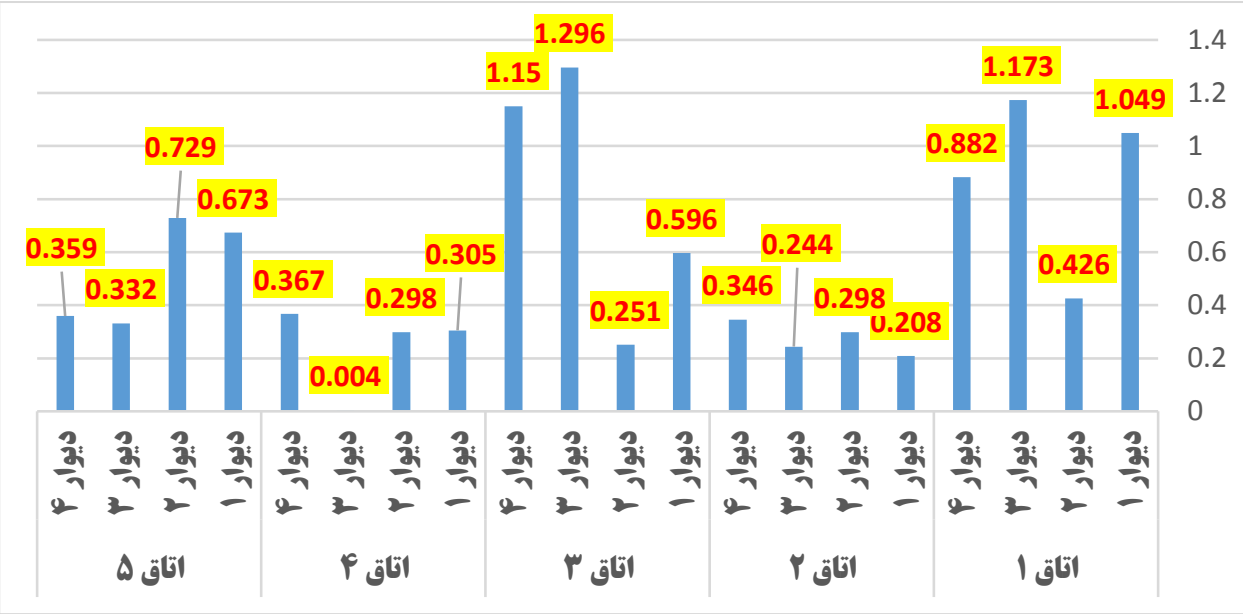

شكل ج: توزيع خطاهاى مطلق براى هر اتاق اسكن شده در واحد متر (A)

Fig. 9: Distribution of absolute errors for each room scanned in meters

جدول سّ: وضعيت رابطه همبستخى بين ابعاد واقعى ديوارها با خطاى مطلق حاصل از اسكنر فروسخ

Table 3: Status of correlation between actual dimensions of walls with absolute error of infrared scanner

\begin{tabular}{|c|c|}
\hline $\begin{array}{c}\text { خطاى مطلق } \\
\text { Absolute Error }\end{array}$ & $\begin{array}{l}\text { آزمون يِيرسون } \\
\text { Pearson Test }\end{array}$ \\
\hline 0.650 & ضريب همبستخىى \\
\hline$* 0.02$ & $\begin{array}{c}\text { سطح معنادارى } \\
\text { Significance Level }\end{array}$ \\
\hline
\end{tabular}

ابعاد واقعى ديوارها

Actual Dimensions of Walls

* معنادارى در سطح بالاتر از صو درصد

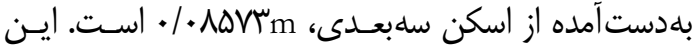
مقدار نشان مىدهد كه خطاهاى نسبى تمايل دارند در اين

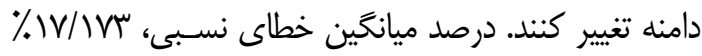

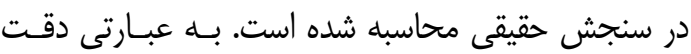

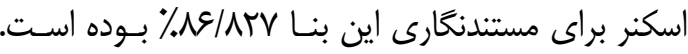

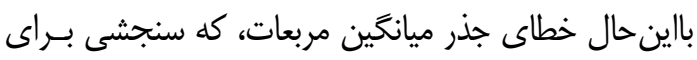

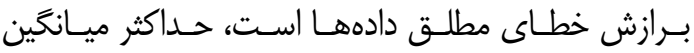

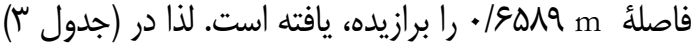
خطاى مطلق ديوارهايى كه يإيينتر از اين مقدار بـوده بــه رنگ سبز و خطاى مطلق ديوارهايى كه بالاتر از اين مقدار

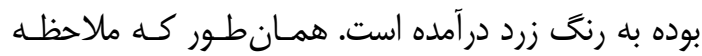

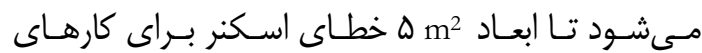
غيرتخصصى مانند استفاده از اسكنر در بازىهاى مبتنى بر واقعيت افزوده قابل قبول است. اعتبـار خطـاى برداشـت از ماند مستندات به شرح زير خواهد بود (جدول ه).
بر اساس آزمون همبستخى ييرسون كه در (جـدول ץ) ارائهشده است، ابعاد ديوارها با خطاى مطلق اسكنر بـ إنه

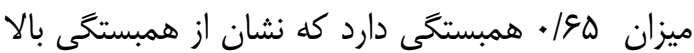

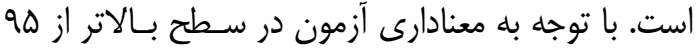
درصد، مىتوان نتيجه گرفت هرجه ابعاد ديوارها بزرگتر مىشود، خطاى اسكنر هم بيشتر مى شود.

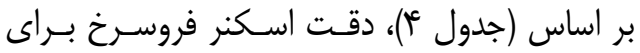
ديوارها با كمترين خطاى مطلق براى ديوار س در اتـاق ع

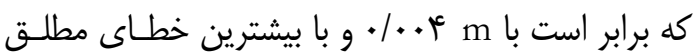

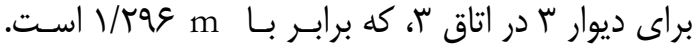
همجنين دقت اسكنر فروسرخ براى اتاقهـا بـا كمتـرين

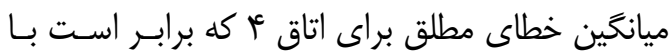

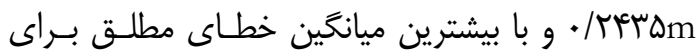

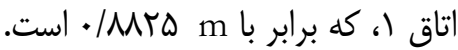
مطابق (جدول ه)، انحــراف معيـار خطاهـاى نسـبـى ابعـاد 
جدول أ: نتايج بdدستآمده از مقايسه تطيبقى ابعاد واقعى خانه و ابعاد بهدستآمده از اسكنر

Table 4: Results from a Comparative Comparison of the Actual Dimensions of the House and the Scanner Dimensions

\begin{tabular}{|c|c|c|c|c|c|c|}
\hline $\begin{array}{c}\text { خطاى نسبى } \\
\text { Relative } \\
\text { Error }\end{array}$ & 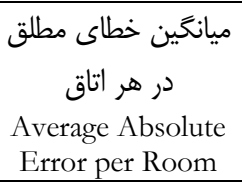 & $\begin{array}{c}\text { خطاى مطلق } \\
\text { Absolute } \\
\text { Error }\end{array}$ & $\begin{array}{c}\text { ابعاد بلدستآمده ازكنر (متر) } \\
\text { Scanner } \\
\text { Dimensions (m) } \\
\text { Diment }\end{array}$ & $\begin{array}{c}\text { ابعاد واقعى (متر) } \\
\text { Actual } \\
\text { Dimensions (m) }\end{array}$ & $\begin{array}{c}\text { ابعاد } \\
\text { Dimensions }\end{array}$ & $\begin{array}{c}\text { اتاق } \\
\text { Room }\end{array}$ \\
\hline 0.23944305 & \multirow{4}{*}{0.8825} & 1.049 & 3.332 & 4.381 & $\begin{array}{l}\text { ديوار } 1 \\
\text { Wall } 1 \\
\end{array}$ & \multirow{4}{*}{$\begin{array}{c}\text { اتاق } 1 \\
\text { Room } \\
1\end{array}$} \\
\hline 0.189081225 & & 0.426 & 1.827 & 2.253 & $\begin{array}{l}\text { ديوار } \\
\text { Wall } 2 \\
\end{array}$ & \\
\hline 0.399659284 & & 1.173 & 1.762 & 2.935 & 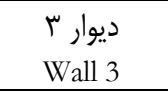 & \\
\hline 0.201048553 & & 0.882 & 3.505 & 4.387 & $\begin{array}{l}\text { ديوار } 4 \\
\text { Wall } 4\end{array}$ & \\
\hline 0.081600628 & \multirow{4}{*}{0.274} & 0.208 & 2.341 & 2.549 & $\begin{array}{l}\text { ديوار } 1 \\
\text { Wall } 1 \\
\end{array}$ & \multirow{4}{*}{$\begin{array}{c}r \text { اتاق } \\
\text { Room } \\
2\end{array}$} \\
\hline 0.067681127 & & 0.298 & 4.105 & 4.403 & $\begin{array}{l}\text { ديوار } 2 \\
\text { Wall } 2\end{array}$ & \\
\hline 0.095761381 & & 0.244 & 2.304 & 2.548 & $\begin{array}{l}\text { ديوار } 13 \\
\text { Wall } 3\end{array}$ & \\
\hline 0.079503676 & & 0.346 & 4.006 & 4.352 & $\begin{array}{l}\text { ديوار } 4 \\
\text { Wall } 4\end{array}$ & \\
\hline 0.124089111 & \multirow{4}{*}{0.82325} & 0.596 & 4.207 & 4.803 & $\begin{array}{l}1 \text { ديوار } 1 \\
\text { Wall } 1 \\
\end{array}$ & \multirow{4}{*}{$\begin{array}{c}\text { اتاق } \\
\text { Room } \\
3\end{array}$} \\
\hline 0.052797644 & & 0.251 & 4.503 & 4.754 & $\begin{array}{l}\text { ديوار } 2 \\
\text { Wall } 2\end{array}$ & \\
\hline 0.154193932 & & 1.296 & 7.109 & 8.405 & $\begin{array}{l}\text { ديوار } 13 \\
\text { Wall } 3\end{array}$ & \\
\hline 0.14100049 & & 1.15 & 7.006 & 8.156 & $\begin{array}{l}\text { ديوار } 4 \\
\text { Wall } 4\end{array}$ & \\
\hline 0.069208078 & \multirow{4}{*}{0.2435} & 0.305 & 4.102 & 4.407 & $\begin{array}{l}\text { ديوار } 1 \\
\text { Wall } 1\end{array}$ & \multirow{4}{*}{ 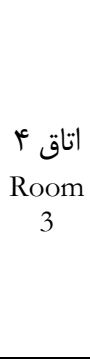 } \\
\hline 0.06616341 & & 0.298 & 4.206 & 4.504 & $\begin{array}{l}\text { ديوار } 2 \\
\text { Wall } 2\end{array}$ & \\
\hline 0.002098636 & & 0.004 & 1.902 & 1.906 & $\begin{array}{l}\text { ديوار } 13 \\
\text { Wall } 3\end{array}$ & \\
\hline 0.195733333 & & 0.367 & 1.508 & 1.875 & $\begin{array}{l}\text { ديوار } 4 \\
\text { Wall } 4\end{array}$ & \\
\hline 0.126861451 & \multirow{4}{*}{0.52325} & 0.673 & 4.632 & 5.305 & $\begin{array}{l}\text { ديوار I } 1 \\
\text { Wall }\end{array}$ & \multirow{4}{*}{$\begin{array}{c}\text { اتاق Doom } \\
\text { Rom }\end{array}$} \\
\hline 0.138645873 & & 0.729 & 4.529 & 5.258 & $\begin{array}{l}\text { ديوار } 2 \\
\text { Wall } 2\end{array}$ & \\
\hline 0.099819603 & & 0.332 & 2.994 & 3.326 & $\begin{array}{l}\text { ديوار } 13 \\
\text { Wall } 3\end{array}$ & \\
\hline 0.110359668 & & 0.359 & 2.894 & 3.253 & $\begin{array}{l}\text { ديوار } 4 \\
\text { Wall } 4\end{array}$ & \\
\hline
\end{tabular}


از دادههاى باكيفيت براى مديريت و امنيت حق مالكيـت موردنياز است. بر اساس ميـانخين خطـاى نسـبى نتـايج سنسور فروسرخ مطـابق مقـررات نقشــــ كشـى كاداسـتر

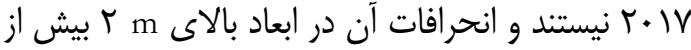

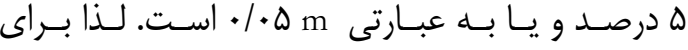

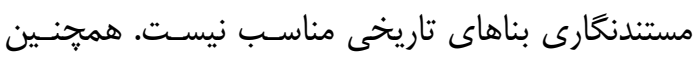

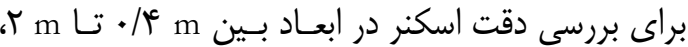

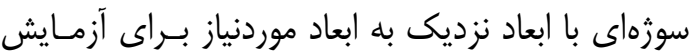

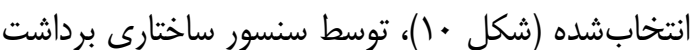
و ابر نقاط بdدستآمده (شكل (1) يردازش شده، سـيس دقت برداشتها ارزيابىشده است.

بر اساس (جدول ع) ميانگين خطاى نسبى برابـر بـاسـا

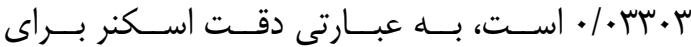

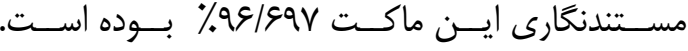

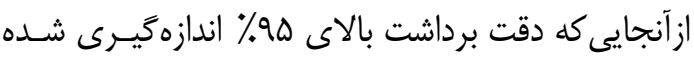

$$
\text { خطاى آن قابلقبول است. }
$$

جدول ه: دادههاى توصيفى اسكنر

Table 5: Descriptive Data of Scanner

\begin{tabular}{|c|c|}
\hline 0.08573 & $\begin{array}{c}\text { انحراف معيار خطاهاى نسبى } \\
\text { Standard deviation relative errors }\end{array}$ \\
\hline 0.007 & $\begin{array}{c}\text { واريانس خطاهاى نسبى } \\
\text { Variance of relative errors } \\
\end{array}$ \\
\hline 0.131738 & $\begin{array}{c}\text { ميانگين خطاى نسبى } \\
\text { Mean Relative Error }\end{array}$ \\
\hline 0.659825 & $\begin{array}{l}\text { خطاى جذر ميانگين مربعات } \\
\text { Root-Mean-Square Error }\end{array}$ \\
\hline
\end{tabular}

دقت خروجىها بر اساس تجزيلوتحليـل معيارهـاى

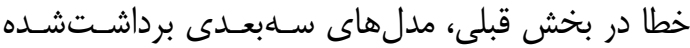

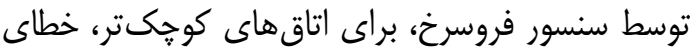
كمترى نسبت به ابعاد حقيقى داشته است و هرجيه ابعـاد بالاتر رفته اين خطاها بيشتر شده اسـت. طبـق مقـررات

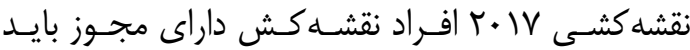

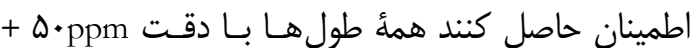

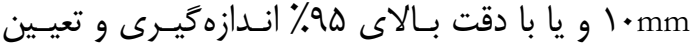
شدهاند. اين ميزان از دقت براى اطمينان حاصـل كـردن

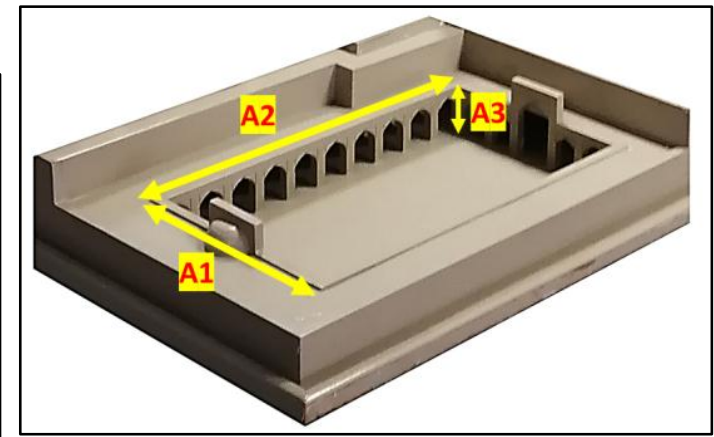

شكل •(: ماكت مسجد امام اصفهان

Fig. 10: Replica of Imam Isfahan Mosque

شكل || (اسكن سلبعدى ماكت مسجد

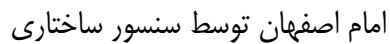
Fig. 11: 3D scanning of the Imam Mosque of Esfahan by structural sensor

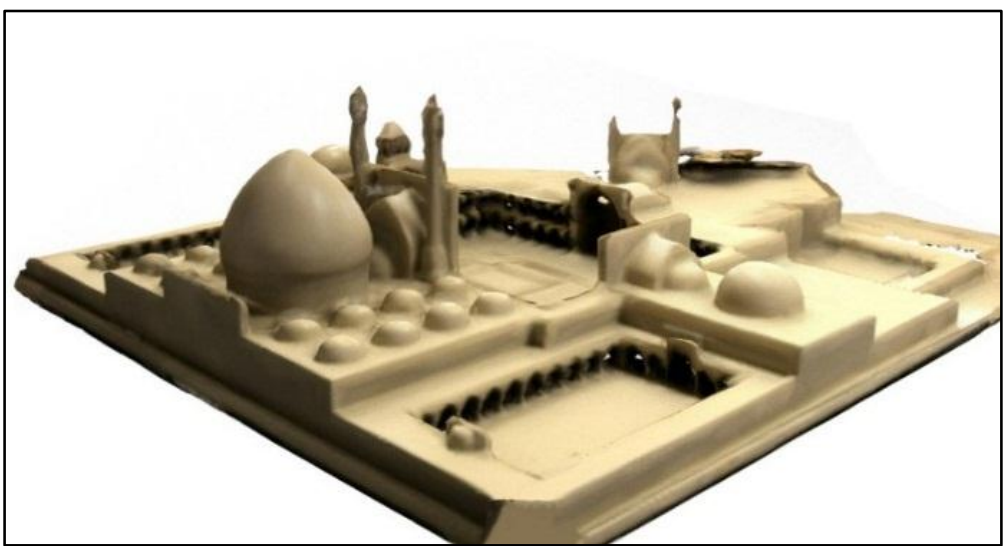

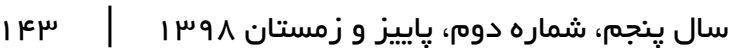


جدول وء نتايج بهدستآمده از مقايسه تطيبقى ابعاد واقعى ماكت و ابعاد بهدستآمده از اسكنر

Table 6: Results from a Comparative Comparison of the Actual Dimensions of the replica and the Scanner Dimensions

\begin{tabular}{|c|c|c|c|c|}
\hline $\begin{array}{c}\text { خطاى نسبى } \\
\text { Relative Error }\end{array}$ & $\begin{array}{c}\text { خطاى مطلق } \\
\text { Absolute Error }\end{array}$ & $\begin{array}{l}\text { ابعاد بهدست آمده از اسكنر (متر) } \\
\text { Scanner Dimensions (m) }\end{array}$ & $\begin{array}{l}\text { ابعاد واقعى (متر) } \\
\text { Actual Dimensions (m) }\end{array}$ & $\begin{array}{c}\text { ابعاد } \\
\text { Dimensions }\end{array}$ \\
\hline 0.00901 & 0.003 & 0.33 & 0.333 & A1 \\
\hline 0.00161 & 0.001 & 0.62 & 0.621 & A2 \\
\hline 0.125 & 0.01 & 0.07 & 0.08 & A3 \\
\hline 0.0098 & 0.02 & 2.02 & 2.04 & B1 \\
\hline 0.02247 & 0.06 & 2.61 & 2.67 & $\mathrm{~B} 2$ \\
\hline 0.0303 & 0.005 & 0.16 & 0.165 & B3 \\
\hline
\end{tabular}

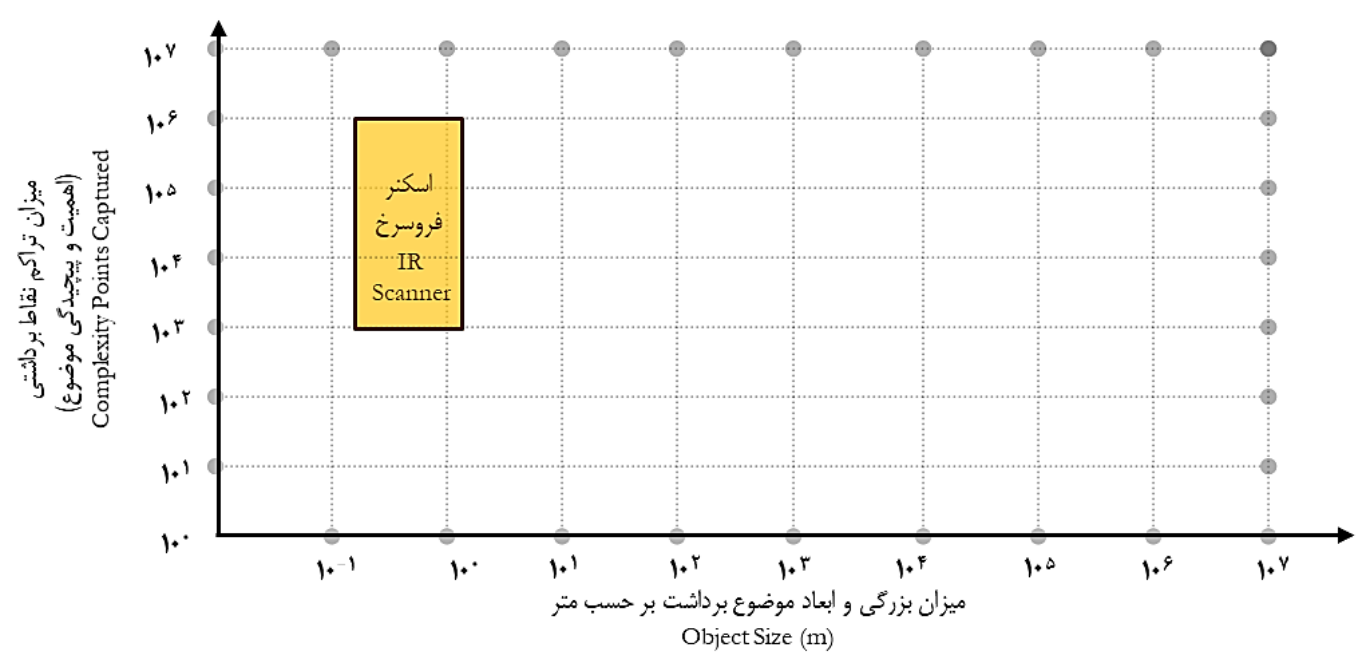

شكل r ا: قابليت اسكنر فروسخ بر اساس تراكم ابر نقاط و ابعاد موضوع

Fig. 12: Capability of Infrared Scanner Based on Point Clouds Density and Subject Dimensions

\section{ع. نتيجه كَيرى}

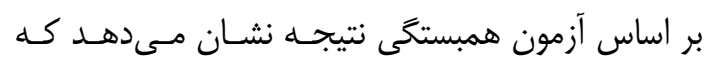

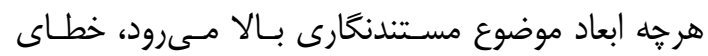

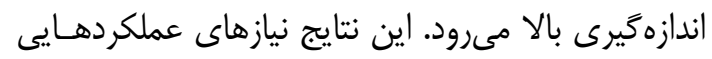

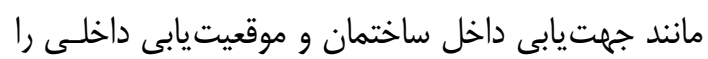

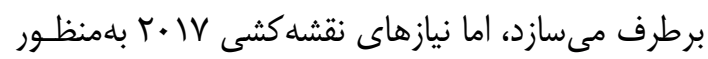

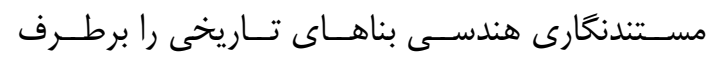

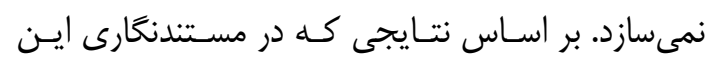
يروزه با سيستم اسكنر فروسرخ حاصل شد، مىتوان بيان

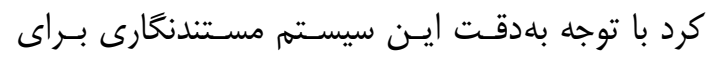

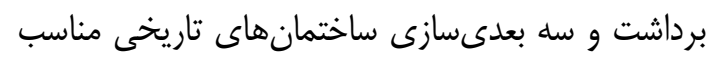

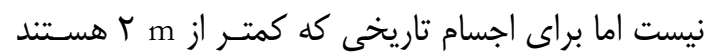

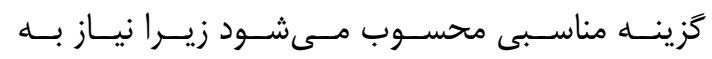

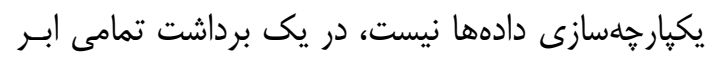

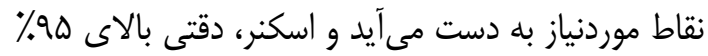

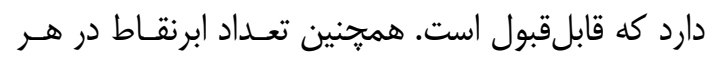

بنابر اين بر اساس اطلاعات بهدستآمده مىتوان به سؤال يخوهش پاسخ داد، دقت بالاى 99٪ كه سـازندكان

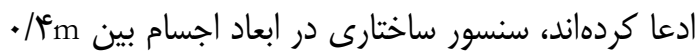
تا m m m داراست درست نيست و شعارى تبليغاتى است.

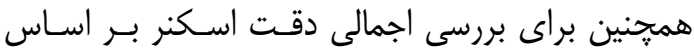

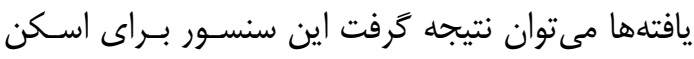

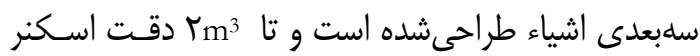

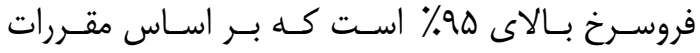

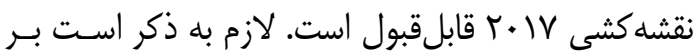
اساس آزمايش انجامشده، اسكنر فروسرخ اجسـام منفـرد

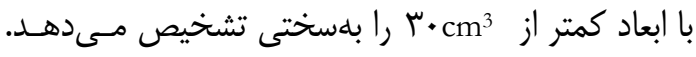
بنابر اين افراد متخصص و غيرمتخصص باد با انتخاب دامنـــ

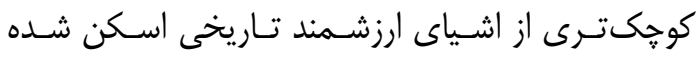
(r.cm)

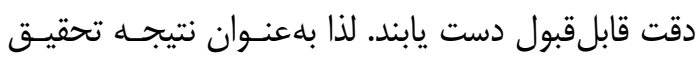
مىتوان نمودار (شكل rا) را ترسيهم نمود.

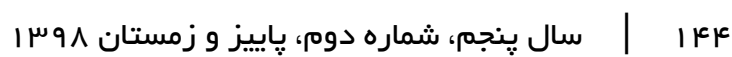




$$
\begin{aligned}
& \text { تدوين روش تحقيق براى تدوين رساله دكترى نغارنــده }
\end{aligned}
$$

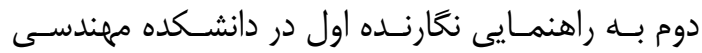

$$
\begin{aligned}
& \text { معمارى و شهرسازى، دانشكاه تربيت دبير شهيد رجايى } \\
& \text { است كه هماكنون در حال انجام است. }
\end{aligned}
$$

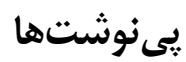

1. Surveying and Spatial Information Regulation. 2017. under the Surveying and Spatial Information Act 2002

2. In making a survey, a surveyor must measure all lengths to an accuracy of $10 \mathrm{~mm}+50$ parts per million or better at a confidence level of $95 \%$.

3. Calculated by Editable Poly Surface

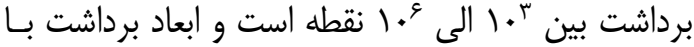

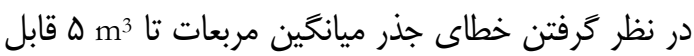

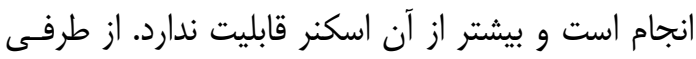

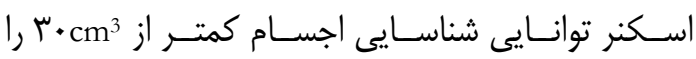

$$
\begin{aligned}
& \text { بلستخى دارد. }
\end{aligned}
$$

$$
\text { سباسگَزارى }
$$

در كمال احترام، از جناب آقايان مهندس عليرضاري استوار،

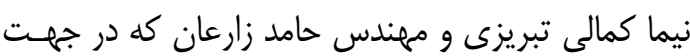

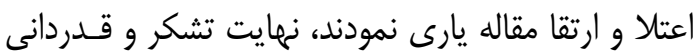
را داريم.

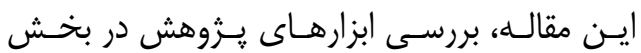

Photogrammetry for Cultural Heritage Applications. InInternational Workshop on Computational Color Imaging 2015 Mar 24 (pp. 208-224). S. [doi.org/10.1007/978-3-319-15979-9_20]

[8] Mahajan A, Bharti V, Singh HP, Josyula L, Kumar P. Construction of a 3D Map of Indoor Environment. Procedia Computer Science. 2018 Jan 1;125:12431. [doi.org/10.1016/j.procs.2017.12.018]

[9] Remondino F, Rizzi A. Reality-based 3D documentation of natural and cultural heritage sites-techniques, problems, and examples. Applied Geomatics. 2010 Sep 1;2(3):85-100. [doi.org/10.1007/s12518010-0025-x]

[10] Curless B, Seitz S. 3D Photography. Course Notes for SIGGRAPH 2000. 2000 Jul.

[11] Zhang W, Wang C, Xi X. 3D Scan of Ornamental Column (huabiao) Using Terrestrial LiDAR and Hand-held Imager. The International Archives of Photogrammetry, Remote Sensing and Spatial Information Sciences. 2015;40(5):491.

[doi.org/10.5194/isprsarchives-XL-5W7-491-2015]

[12] Bok Y, Jeong Y, Choi DG, Kweon IS. Capturing village-level heritages with a hand-held camera-laser fusion sensor. International Journal of Computer Vision. 2011 Aug 1;94(1):36-53. Journal of Cultur Heritage. $\quad 2019$ Jan 1;35:16-24 [doi.org/10.1016/j.culher.2018.07.013]

[7] Serna CG, Pillay R, Trémeau A. Data fusion of objects using techniques such as Laser Scanning, Structured Light and 
[doi.org/10.1007/s11263-010-0397-8]

[13] Blake B, Bedford J. Documentation for conservation, a manual for teaching metric survey skills. 2008.

[14] Microsoft Kinect. [(Accessed on 10 September 2015)]; Available online: http://www.xbox.com/en-US/xboxone/accessories/kinect-for-xbox-one.

[15] Anguelov D, Srinivasan P, Koller D, Thrun S, Rodgers J, Davis J. SCAPE: shape completion and animation of people. InACM SIGGRAPH 2005 Papers 2005 Jul 1 (pp. 408-416). [doi.org/10.1145/1073204.1073207]

[16] Mao A, Zhang H, Liu Y, Zheng Y, Li G, Han G. Easy and fast reconstruction of a 3D avatar with an RGB-D sensor. Sensors. $2017 \quad$ May;17(5):1113. [doi.org/10.3390/s17051113]

[17] Beňo P, Duchoň F, Tölgyessy M, Hubinský P, Kajan M. 3d map reconstruction with sensor kinect: Searching for solution applicable to small mobile robots. In 2014 23rd International Conference on Robotics in Alpe-AdriaDanube Region (RAAD) 2014 Sep 3 (pp. 1-6). [doi.org/10.1109/RAAD.2014.7002252]

[18] Freedman B, Shpunt A, Machline M, Arieli Y, inventors; PrimeSense Ltd, assignee. Depth mapping using projected patterns. United States patent US 8,493,496. 2013 Jul 23.

[19] Kalantari M, Nechifor M. Accuracy and utility of the Structure Sensor for collecting 3D indoor information. Geospatial information science. $2016 \mathrm{Jul}$ 2;19(3):202-9.

[doi.org/10.1080/10095020.2016.123581 7]

[20] Weiss A, Hirshberg D, Black MJ. Home 3D body scans from noisy image and range data. In2011 International Conference on Computer Vision 2011 Nov 6 (pp. 1951-1958). IEEE. [doi.org/10.1109/ICCV.2011.6126465]

[21] Tong J, Zhou J, Liu L, Pan Z, Yan H. Scanning 3d full human bodies using kinects. IEEE transactions on visualization and computer graphics. 2012 Mar 9;18(4):643-50. [doi.org/10.1109/TVCG.2012.56]

[22] Cui Y, Chang W, Nöll T, Stricker D. KinectAvatar: fully automatic body capture using a single kinect. InAsian Conference on Computer Vision 2012 Nov 5 (pp. 133-147). Springer, Berlin, Heidelberg. [doi.org/10.1007/978-3-64237484-5_12]

[23] Li H, Vouga E, Gudym A, Luo L, Barron JT, Gusev G. 3D self-portraits. ACM Transactions on Graphics (TOG). 2013 Nov 1;32(6):1-9. [doi.org/10.1145/2508363.2508407]

[24] Chen Y, Dang G, Cheng ZQ, Xu K. Fast capture of personalized avatar using two Kinects. Journal of Manufacturing Systems. 2014 Jan 1;33(1):233-40. [doi.org/10.1016/j.jmsy.2013.11.005]

[25] Zhu H, Yu Y, Zhou Y, Du S. Dynamic human body modeling using a single RGB camera. Sensors. 2016 Mar;16(3):402. [doi.org/10.3390/s16030402]

[26] Khoshelham K, Elberink SO. Accuracy and resolution of kinect depth data for indoor mapping applications. Sensors. 2012 Feb;12(2):1437-54. [doi.org/10.3390/s120201437]

[27] Canessa A, Chessa M, Gibaldi A, Sabatini SP, Solari F. Calibrated depth and color cameras for accurate 3D interaction in a stereoscopic augmented reality environment. Journal of Visual Communication and Image Representation. 2014 Jan 1;25(1):227-37. [doi.org/10.1016/j.jvcir.2013.02.011]

[28] Herrera D, Kannala J, Heikkilä J. Joint depth and color camera calibration with distortion correction. IEEE Transactions on Pattern Analysis and Machine Intelligence. 2012 May 29;34(10):2058-64. [doi.org/10.1109/TPAMI.2012.125]

[29] Zhang Z. A flexible new technique for camera calibration. IEEE Transactions on pattern analysis and machine intelligence. 2000 Nov;22(11):1330-4. [doi.org/10.1109/34.888718]

[30] Smisek J, Jancosek M, Pajdla T. 3D with Kinect. InConsumer depth cameras for computer vision 2013 (pp. 3-25). Springer, London. [doi.org/10.1007/9781-4471-4640-7_1]

[31] Herrera D, Kannala J, Heikkilä J. Accurate and practical calibration of a depth and color camera pair. InInternational Conference on Computer analysis of images and patterns 2011 Aug 
29 (pp. 437-445). Springer, Berlin, Heidelberg. [doi.org/10.1007/978-3-64223678-5_52]

[32] Yamazoe H, Habe H, Mitsugami I, Yagi Y. Easy depth sensor calibration. InProceedings of the 21st International Conference on Pattern Recognition (ICPR2012) 2012 Nov 11 (pp. 465-468). IEEE.

[33] Raposo C, Barreto JP, Nunes U. Fast and accurate calibration of a kinect sensor. In2013 International Conference on 3D Vision-3DV 20132013 Jun 29 (pp. 342-349). IEEE. [doi.org/10.1109/3DV.2013.52]

[34] Zhang C, Zhang Z. Calibration between depth and color sensors for commodity depth cameras. InComputer vision and machine learning with RGB-D sensors 2014 (pp. 47-64). Springer, Cham. [doi.org/10.1007/978-3-319-08651-4_3]

[35] Zollhöfer M, Martinek M, Greiner G, Stamminger M, Süßmuth J. Automatic reconstruction of personalized avatars from 3D face scans. Computer Animation and Virtual Worlds. 2011 Apr;22(2-3):195-202. [doi.org/10.1002/cav.405]

[36] Berdnikov Y, Vatolin D. Real-time depth map occlusion filling and scene background restoration for projectedpattern based depth cameras. InGraphic Conf., IETP 2011.

[37] Qi F, Han J, Wang P, Shi G, Li F. Structure guided fusion for depth map inpainting. Pattern Recognition Letters. 2013 Jan 1;34(1):70-6. [doi.org/10.1016/j.patrec.2012.06.003]

[38] Schmeing M, Jiang X. Color segmentation based depth image filtering. InInternational Workshop on Depth Image Analysis and Applications 2012 Nov 11 (pp. 68-77). Springer, Berlin, Heidelberg. [doi.org/10.1007/978-3-64240303-3_8]

[39] Chen L, Lin H, Li S. Depth image enhancement for Kinect using region growing and bilateral filter. InProceedings of the 21st International Conference on Pattern Recognition (ICPR2012) 2012 Nov 11 (pp. 3070-3073). IEEE.

[40] Hornacek M, Rhemann C, Gelautz M, Rother C. Depth super resolution by rigid body self-similarity in $3 \mathrm{~d}$. InProceedings of the IEEE conference on computer vision and pattern recognition 2013 (pp. 1123-1130). [doi.org/10.1109/CVPR.2013.149]

[41] Hu X, yuan Yu Y, zhong Wang Z. HighDefinition 3D Reconstruction in RealTime from a Moving Depth Sensor. In2013 International Conference on Advanced Computer Science and Electronics Information (ICACSEI 2013) 2013 Aug. Atlantis Press. [doi.org/10.2991/icacsei.2013.94]

[42] Henry P, Krainin M, Herbst E, Ren X, Fox D. RGB-D mapping: Using depth cameras for dense 3D modeling of indoor environments. InExperimental robotics 2014 (pp. 477-491). Springer, Berlin, Heidelberg. [doi.org/10.1007/978-3-642-28572-1_33]

[43] Newcombe RA, Izadi S, Hilliges O, Molyneaux D, Kim D, Davison AJ, Kohi P, Shotton J, Hodges S, Fitzgibbon A. KinectFusion: Real-time dense surface mapping and tracking. In2011 10th IEEE. International Symposium on Mixed and Augmented Reality 2011 Oct 26 (pp. 127-136). IEEE. [doi.org/10.1109/ISMAR.2011.6092378]

[44] Izadi S, Newcombe RA, Kim D, Hilliges O, Molyneaux D, Hodges S, Kohli P, Shotton J, Davison AJ, Fitzgibbon A. Kinectfusion: real-time dynamic 3d surface reconstruction and interaction. InACM SIGGRAPH 2011 Talks 2011 Aug 7 (p. 23). ACM. [doi.org/10.1145/2037826.2037857]

[45] Taher Tolou Del M.S, Kamali Tabrizi S. Interpretation of Architectural Elements in the Integrated Style of Etemad alSaltaneh House of Tehran, First National Conference on Documentation of Natural and Cultural Heritage, Tehran, Shahid Rajaee University, 2016. [in Persian]

[ طاهرطلوع دل محمدصـادق، كمـالى تبريـزى سـينا.

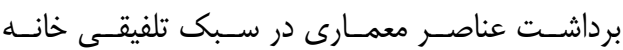

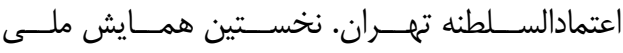
مستندنگارى ميراث طبيعى و فرهنَّى، تهران، دانشگاه

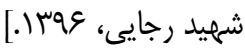

[46] Pearson K. VII. Note on regression and inheritance in the case of two parents. Proceedings of the royal society of 
London. 1895 Dec 31;58(347-352):240-2.

[doi.org/10.1098/rspl.1895.0041] 